Article

\title{
Hydrogen Trapping in bcc Iron
}

\author{
Anastasiia S. Kholtobina ${ }^{1,2, *}$, Reinhard Pippan ${ }^{3}$, Lorenz Romaner ${ }^{1}$, Daniel Scheiber ${ }^{1}(\mathbb{D}$, \\ Werner Ecker $^{1}$ (D) and Vsevolod I. Razumovskiy ${ }^{1}$ \\ 1 Materials Center Leoben Forschung GmbH, Roseggerstraße 12, 8700 Leoben, Austria; \\ lorenz.romaner@mcl.at (L.R.); daniel.scheiber@mcl.at (D.S.); werner.ecker@mcl.at (W.E.); \\ razvsevol@yahoo.com (V.I.R.) \\ 2 Department Materials Physics, University of Leoben, Jahnstraße 12, 8700 Leoben, Austria \\ 3 Erich Schmid Institut of Materials Science, Austrian Academy of Sciences, Jahnstraße 12, \\ 8700 Leoben, Austria; reinhard.pippan@oeaw.ac.at \\ * Correspondence: anastasiia.kholtobina@gmail.com
}

Received: 20 April 2020; Accepted: 12 May 2020; Published: 15 May 2020

check for updates

\begin{abstract}
Fundamental understanding of $\mathrm{H}$ localization in steel is an important step towards theoretical descriptions of hydrogen embrittlement mechanisms at the atomic level. In this paper, we investigate the interaction between atomic $\mathrm{H}$ and defects in ferromagnetic body-centered cubic (bcc) iron using density functional theory (DFT) calculations. Hydrogen trapping profiles in the bulk lattice, at vacancies, dislocations and grain boundaries (GBs) are calculated and used to evaluate the concentrations of $\mathrm{H}$ at these defects as a function of temperature. The results on $\mathrm{H}$-trapping at GBs enable further investigating $\mathrm{H}$-enhanced decohesion at GBs in Fe. A hierarchy map of trapping energies associated with the most common crystal lattice defects is presented and the most attractive H-trapping sites are identified.
\end{abstract}

Keywords: first principles calculations; hydrogen embrittlement; bcc iron; trapping energies

\section{Introduction}

Hydrogen embrittlement (HE) is a latent problem for structural materials, particularly for high-strength steels [1-3]. In spite of multiple existing theories of HE mechanisms [3], the actual cause of embrittlement remains unclear and requires further investigation in many cases. Density functional theory (DFT) offers a predictive methodology to study this problem at the atomic level and can provide answers to some important questions, such as $\mathrm{H}$ localization at defects and its impact on the interatomic bonding and cohesion in the system [4-6]. Furthermore, these data can be used to support or discard existing theories of $\mathrm{HE}$; estimate the actual content of atomic $\mathrm{H}$ in the material in general and at the defects in particular; and assist in the interpretation of thermal desorption spectroscopy [7,8] data.

A significant amount of effort has been made with respect to investigations of H-trapping in Fe [9-21]. Most research works have focused on the identification of the most favorable position of the atomic $\mathrm{H}$ in the lattice or at a defect with the lowest trapping energy at $0 \mathrm{~K}$. The data available in the literature suggest that the strongest traps for $\mathrm{H}$ at $0 \mathrm{~K}$ should be some special grain boundaries (GBs) [13,22]. Hydrogen trapping at special coincident site lattice (CSL) GBs has been described so far for the tilt $\Sigma 3(111), \Sigma 5(012), \Sigma 5(013)$ [13], $\Sigma 9(1 / 211), \Sigma 13(1 / 311), \Sigma 17(1 / 411)$ [15], and twist $\Sigma 3(110), \Sigma 9(110), \Sigma 11(110), \Sigma 17(110)$ [14] GBs. Trapping energies as strong as $-0.81 \mathrm{eV},-0.83 \mathrm{eV}$ and $-0.95 \mathrm{eV}$ have been found for the $\Sigma 5(012)$ [100] tilt GB [13], and the $\Sigma 11(110)$ and $\Sigma 17(110)$ twist GBs [14], respectively. DFT studies on H-trapping at the edge and screw dislocations $[16,17,23]$ suggest a range of the trapping energies from -0.19 to $-0.47[16,17,23]$; i.e., sizeably lower values than those of the special GBs. Other DFT papers with a focus on H-trapping at vacancies and on formation of vacancy-H clusters in body-centered cubic (bcc) Fe report trapping energies varying from -0.4 to 
$-0.6 \mathrm{eV}[12,18,24]$, which are also lower than those of GBs. However, it is rather difficult to draw a definite conclusion on the hierarchy of trapping energies, as most of the aforementioned results have been obtained using different methods and approaches, which makes a quantitative comparison difficult or even impossible in some cases.

The problem gets even more involved when one starts considering not just the strongest trapping site, but the whole distribution of the trapping energies associated with a particular defect $[25,26]$. So far, only a few works have considered such distributions [4,27] and none have provided a systematic investigation of H-trapping energy distributions for the key defects using the same DFT methodology. Such an investigation is still required to evaluate the possible concentrations of $\mathrm{H}$ atoms at different defects at ambient temperatures relevant to the conditions at which HE occurs.

The presence of traps in the bcc Fe significantly influences the diffusivity of $\mathrm{H}$, and therefore is an important aspect of the problem of $\mathrm{HE}$ in Fe. This point has been thoroughly investigated in a number of DFT and molecular dynamics (MD) studies for each of the considered defects in our work. In the case of bcc Fe, the $\mathrm{H}$ diffusivity in the presence of traps has been reported to be significantly lower than in the Fe lattice. Lu et al. [28] reported that diffusivities were reduced as the point defect concentration increased, and the influence of such point defects as Fe vacancies and self-interstitial atoms reduces as the temperature increases. Lv et al. also found changes in the mechanism of $\mathrm{H}$ diffusivity at the presence of vacancies [29]. Kimizuka et al. showed that the $\mathrm{H}$ atom was strongly trapped at screw dislocations, and there is a high barrier for $\mathrm{H}$ diffusion both across and along the dislocation [30]. According to Teus et al., Fe GBs retard H migration [31]. Jiang et al. showed high diffusion barriers of $\mathrm{H}$ migration from surfaces $\mathrm{Fe}(110)(1.02 \mathrm{eV})$ and $\mathrm{Fe}(100)(0.38 \mathrm{eV})$ to subsurface layers and very small barrier for the reverse process $(0.03 \mathrm{eV})$ [32]. Activation migration energies for $\mathrm{H}$ at all aforementioned defects were given in the literature: 0.037 [31], 0.024 [28], 0.088 [32] and $0.127 \mathrm{eV}$ [33] for bulk; $0.232 \mathrm{eV}$ in the presence of Fe vacancies at a concentration of $0.009 \%$ [28]; $0.314 \mathrm{eV}$ at $\Sigma 5(013)$ [31]; and $0.43 \mathrm{eV}$ along [111] direction in the system with screw dislocations [30]. The thermodynamics-based trap-diffusion model by Svoboda and Fischer [34,35] directly links the trapping energies and the trap densities to the diffusivity of $\mathrm{H}$. They clearly presented how the diffusivity gets concentration dependent in the presence of traps. Drexler et al. recently applied this generalized Oriani approach for the model-based evaluation of thermal desorption experiments and related the results to DFT-calculated trapping energies [36,37].

In this work, we perform a systematic DFT investigation of H-trapping in the bulk lattice, at vacancies, dislocations and special GBs in ferromagnetic bcc Fe. In comparison to previous theoretical studies using different variations of the generalized gradient approximation (GGA) for the exchange-correlation functional or even less precise tight-binding (TB) approximation calculations, this study provides a consistent set of $\mathrm{H}$-trapping energies obtained within the same methodological approach that provides a set of energies for qualitative and quantitative interpretation of experimental (for instance, thermal desorption spectroscopy) data. We propose to use the results of this investigation for a hierarchical analysis of $\mathrm{H}$-trapping in iron and the qualitative comparison of the trapping energies at selected defects. In addition, we study trapping energy profiles near each of the defects and use these data to evaluate $\mathrm{H}$ concentration at the defects as a function of temperature within the framework of a classical segregation isotherm. Finally, we also provide insights into the impact of H-trapping on cohesion in Fe.

\section{Computational Details}

\subsection{Electronic Structure and Total Energy Calculations}

Spin-polarized calculations were performed within the framework of density functional theory (DFT) using the projector augmented wave method [38-41] as implemented in the Vienna Ab-initio Simulation Package (VASP) (5.4.1, Materials Center Leoben Forschung GmbH, Leoben, Austria) [40,42]. Exchange-correlation effects were treated using the generalized gradient approximation (GGA) 
employing the Perdew, Burke and Enzerhof (PBE) [43] scheme. The convergence criteria were, for the total energy, $10^{-5} \mathrm{eV}$, and for the forces, $10^{-3} \mathrm{eV} / \AA$. Ionic relaxations were included in all calculations. The cell shape and volume were kept fixed during the relaxations using the $0 \mathrm{~K}$ equilibrium volume of Fe unless specified otherwise. The calculations were performed using a plane-wave cutoff energy of $400 \mathrm{eV}$. The integration over the Brillouin zone was performed using the Monkhorst-Pack [44] meshes described in the next section in more detail. The VESTA software package [45] was used for visualisation of the atomic structures.

\subsection{Structure Models}

\subsubsection{Bulk}

The equation of state was fitted by the Birch-Murnaghan equation [46,47] for calculation of the Fe bcc lattice parameter and bulk modulus. The supercells of 16, 54 and 128 atoms were employed to investigate $\mathrm{H}$ solution energies in the bulk of bcc iron. The structure models were prepared as the $2 \times 2$ $\times 2,3 \times 3 \times 3,4 \times 4 \times 4$ replications of the two-atom conventional bcc cell. In all VASP calculations, 6 $\times 6 \times 6,4 \times 4 \times 4$ and $4 \times 4 \times 4$ k-point meshes were used for each of the aforementioned supercells respectively. Hydrogen has three possible sites in the bcc Fe lattice: (i) an octahedral interstitial; (ii) a tetrahedral interstitial and (iii) a substitutional site (see Figure 1).

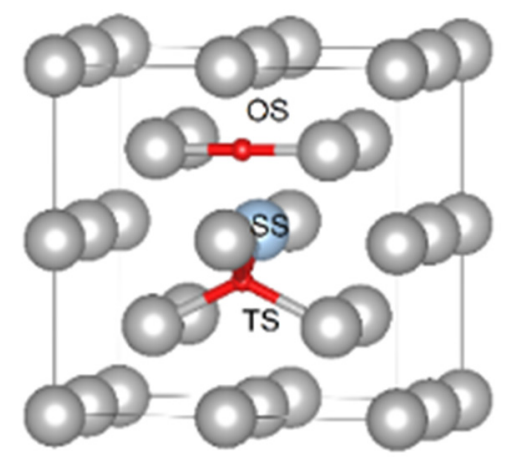

Figure 1. Possible sites for $\mathrm{H}$ in the bulk of bcc Fe. The red spheres correspond to the interstitial positions (OS, TS correspond to the octahedral and tetrahedral sites) and the blue sphere corresponds to the substitutional site (SS).

\subsubsection{Interfaces}

Special CSL model GBs $\Sigma 3(111)$ [1-10], $\Sigma 5$ (012) [100] and $\Sigma 5$ (100) [001] were modelled by supercells containing 49, 30 and 44 atomic layers of Fe (two, one and five atoms per layer) separated by 15,7 and $7 \AA$ of vacuum, which were tested to be sufficient within $0.01 \mathrm{eV} /$ at error at most, as schematically shown in Figure 2.

The same supercells, but without GB, have been used for the (111), (012) and (100) free surface (FS) calculations. The $6 \times 4 \times 1,14 \times 6 \times 1,2 \times 2 \times 1$ Monkhorst-Pack k-point meshes were used for GB and FS calculations. The structures of the $\Sigma 3(111)$ [1-10,26], $\Sigma 5$ (012) [100] [48] and $\Sigma 5$ (100)[001] [26]GBs were relaxed by shifting two grains in the slab with respect to each other. The discovered minimum energy structures were used in all GB slab calculations. Hydrogen atoms were inserted in the interstitial positions one at a time in the first three GB/FS layers starting from the GB/FS plane, as shown in Figure $2 \mathrm{a}-\mathrm{c}(\mathrm{I} 0-\mathrm{I} 2)$. In the case of (120) and (100) FS, only the FS layer (i0) has been considered for H segregation. 


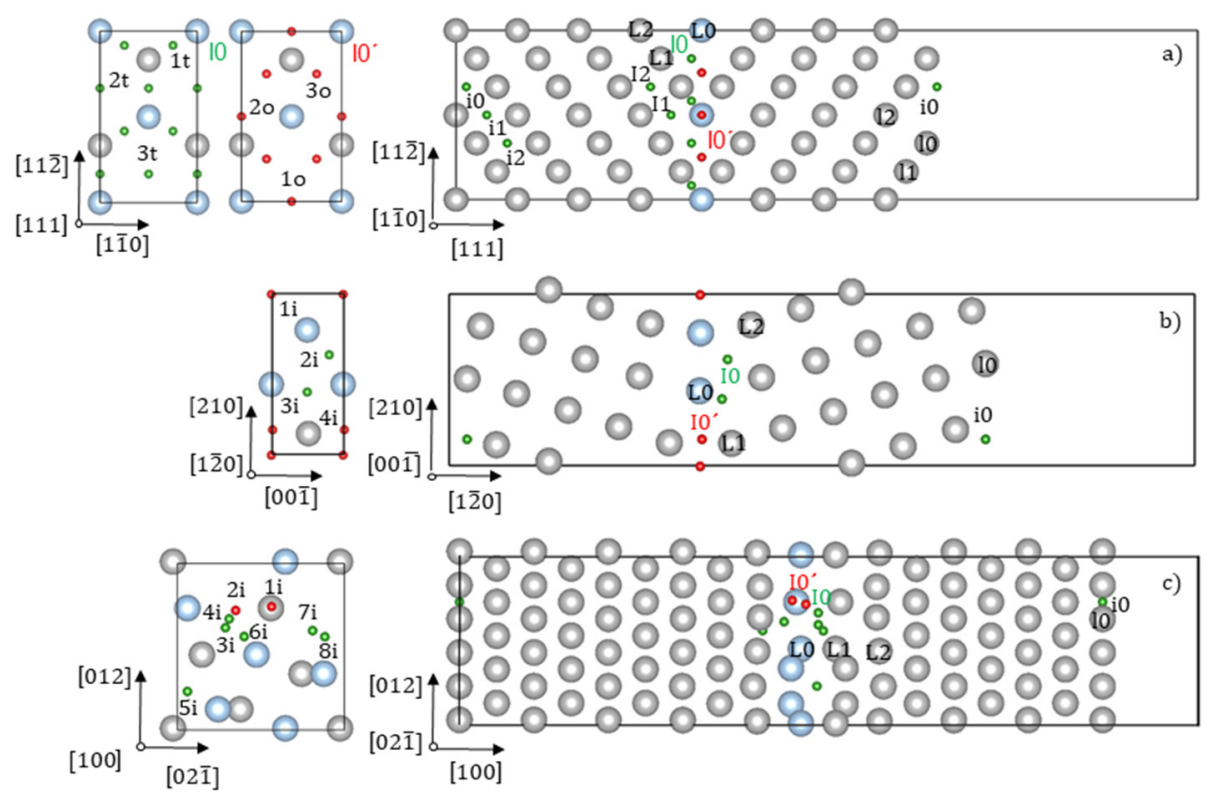

Figure 2. Schematic structures of (a) the coincident site lattice (CSL) $\Sigma 3(111)$ [1-10] grain boundary (GB) and (111) free surface (FS); (b) the CSL $\Sigma 5$ (012) [100] GB and (012) FS; (c) the CSL $\Sigma 5$ (100) [001] GB and (001) FS used in this work. Capital/not capital letters of the numbers of layers and $\mathrm{H}$ positions refer to GB/FS, respectively. The red spheres correspond to $H$ interstitial sites located in the GB plane. The green spheres correspond to $\mathrm{H}$ interstitial sites located outside the GB plane. The view is normal to the GB planes; and no labels are used for the demonstration of the possible tetrahedral and octahedral sites of $\mathrm{H}$ in the I0 and I0' layers for the case of $\Sigma 3(111)$ [1-10] and no labels for the $\mathrm{H}$ positions in the cases of $\Sigma 5$ (012) [100] and $\Sigma 5$ (100) [001]. I0 and I0' labels are referred to the first layer of H located directly at the GB layer and the next to GB layer, which correspond to the octahedral and tetrahedral sites in the case of $\Sigma 3(111)$ [1-10]. The blue spheres correspond to the GB layers.

\subsubsection{Dislocations}

Two dislocations were considered in this work: (i) the $\frac{1}{2}<111>$ screw dislocation and (ii) the mixed M111 dislocation, wherein the Burgers vector and dislocation line are along non-parallel [111] directions intersecting at an angle of about $70.5^{\circ}$. Dislocations were treated in $3 \mathrm{D}$ periodic structures. For the case of the screw dislocation, the quadrupole arrangement was used which had already been proven to reliably describe core structures, energies, and Peierls stresses [49-52]. For the M111 dislocation, a suitable periodic geometry was considered. In both cases, two dislocations with antiparallel Burgers vectors were inserted into unit cells characterized by the following lattice vectors: $a_{1}=5 u_{[11 \overline{2}]}, a_{2}=9 u_{[\overline{110]}}+u_{[111]}$ and $a_{3}=u_{[111]}$ in the screw dislocation case, and $a_{1}=4 u_{[11 \overline{2}]}, a_{2}=11 u_{[\overline{110}]}$ and $a_{3}=u_{[111]}$ in the mixed dislocation case, where $u_{[11 \overline{2}]}, u_{[\overline{1} 10]}, u_{[111]}$ were basis vectors, connecting two atoms of the bcc lattice along the specified direction [53]. The resulting supercell geometries included 135 and 253 atoms, as shown in Figure 3. The k-point meshes were $1 \times 2 \times 16$ and $1 \times 1 \times 16$ for the screw and mixed dislocation respectively, which proved to yield convergent results in earlier works [54,55]. 


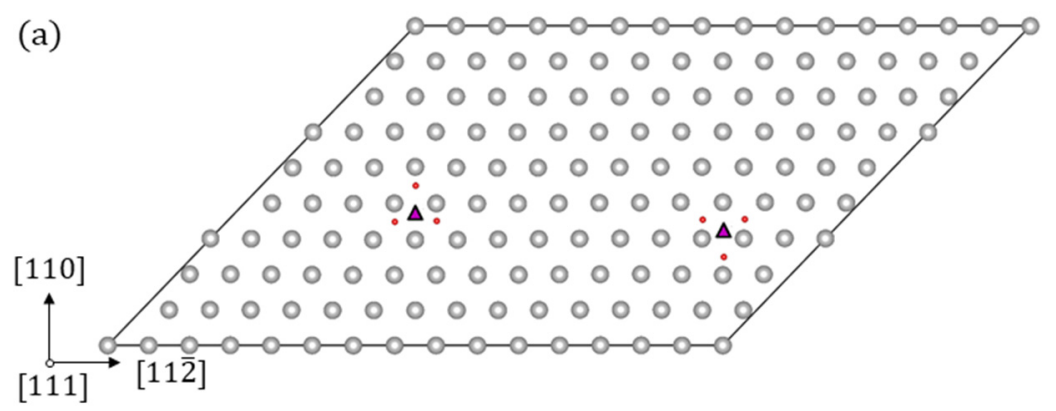

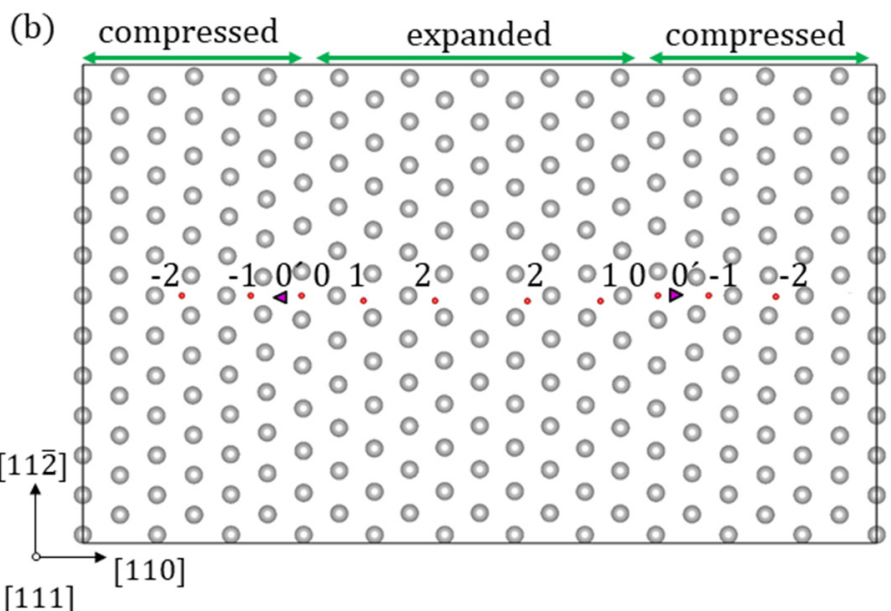

Figure 3. (a) $\frac{1}{2}<111>$ screw and (b) M111 mixed dislocations. The location of the dislocation core is marked as a purple triangle. Initial $\mathrm{H}$ atom positons are marked with the red spheres. The digits -2 , $-1,0,1,2$ are the numbers of $\mathrm{H}$ positions and correspond to Figure 7. $0^{\prime} \mathrm{H}$ position is additionally considered one in the dislocation core, but it was found to be less energetically preferable during the atomic relaxation procedure and therefore is not shown in the H profile in Figure 7.

\section{Methodology}

\subsection{Solution Energies}

The solution energy of the substitutional and interstitial $\mathrm{H}$ is defined as:

$$
\begin{gathered}
\Delta E_{\text {sol }}^{\text {sub }}=E_{s c}[N-1 ; 1]-\frac{N-1}{N} E_{s c}[N ; 0]-\frac{1}{2} E_{H_{2}} \\
\Delta E_{\text {sol }}^{\text {int }}=-\Delta_{\text {bulk }}^{H}-\frac{1}{2} E_{H_{2}} \\
\Delta_{\text {bulk }}^{H}=E_{s c}[N ; 0]-E_{s c}[N ; 1]
\end{gathered}
$$

where $E_{s c}[n ; m]$ represents the total energy of a bulk supercell, containing $n$ host atoms and $\mathrm{m} \mathrm{H}$ atoms; $E_{H_{2}}$ is the total energy of the $\mathrm{H}$ molecule in its equilibrium (fully relaxed) configuration at $0 \mathrm{~K} ; \Delta_{b u l k}^{H}$ is the energy difference between the pure bulk supercell and bulk supercell after $\mathrm{H}$ atom is added.

\subsection{Hydrogen Trapping at Defects}

The energy of $\mathrm{H}$-trapping by a vacancy, a dislocation, the FS and a GB at interstitial positions is defined as:

$$
E_{\text {trap }}^{\text {def }}=E_{s c}^{d e f}[m]-E_{s c}^{d e f}[m-1]+\Delta_{\text {bulk }}^{H}
$$

where $E_{s c}^{d e f}[m]$ and $E_{s c}^{d e f}[m-1]$ represent the total energies of supercells, containing one of the defects (vacancy, dislocation, GB, FS) and $\mathrm{m}$ and $\mathrm{m}-1 \mathrm{H}$ atoms respectively. 
We note that the trapping energies of Equation (4) are defined so that a negative energy means the energetically favored trapping. When we compare several negative trapping energies using "lower" and "higher" wording, then we mean a more negative, i.e., a more trapped energy in the first case, and a less negative, i.e., a less trapped energy in the second case.

\subsection{Effect of H on the Bulk Cohesive Strength}

The partial cohesive energy $\chi_{i}$ is a fundamental quantity that can be used to characterize the effect of $\mathrm{H}$ (with concentration $c_{i}$ ) on the cohesive strength of the bulk of an alloy [56]. In this work, the partial cohesive energy $\chi_{i}$ is calculated as:

$$
\begin{gathered}
\chi_{i}=\frac{\partial E_{c o h}}{\partial c_{i}} c=o=\Delta_{\text {bulk }}^{H}+\left(E_{c o h}^{H}-E_{c o h}^{0}\right)+E_{c r y s t}^{H} \\
E_{c o h}=E_{a t}-E_{c r y s t}
\end{gathered}
$$

where $c_{i}$ is the impurity concentration. $E_{c o h}^{i}$ and $E_{c o h}^{0}$ are the cohesive energies of the impurity and host species, $E_{c r y s t}^{i}$ is the calculated total energies (per atom) of impurities in their respective most stable crystalline phases; $E_{a t}$ is energies of an isolated atom. All these energies are calculated by DFT at $0 \mathrm{~K}$. The bulk supercell chosen for this calculation contains 128 atoms.

\subsection{Effect of Trapping on GB Cohesive Strength}

The ideal work of separation, $W_{\text {sep }}$ is a fundamental thermodynamic quantity that controls the mechanical strength of an interface [57] and can be defined as:

$$
W_{s e p}^{0}=2 \gamma_{f s}^{0}-\gamma_{g b}^{0}
$$

where $\gamma_{f s}^{0}$ is the surface formation energy and $\gamma_{g b}^{0}$ is the GB formation energy, which can be obtained by:

$$
\gamma_{f_{s}}^{0}=\left(E_{\text {slab }}^{f s}[N ; 0]-N_{\text {slab }}^{f s} \varepsilon_{\text {slab }}^{0}\right) / 2 A
$$

where $E_{\text {slab }}^{f_{s}}$ is the total energy of a slab containing the FS, $N_{\text {slab }}^{f_{s}}$ is the number of atoms in the supercell, $\varepsilon_{\text {slab }}^{0}$ is the total energy of the space filling slab (the slab supercell of the same geometry as used for $E_{\text {slab }}^{f s}$ calculations completely filled up with layers of Fe) divided by the number of atoms and $A$ is the cross sectional area of the supercell. The factor of two arises from the fact that there are two FSs per supercell [58]. The supercell, containing a GB, also includes two FSs. If FSs and GBs are chosen so that they contain equal numbers of atoms, we can define the GB energy as:

$$
\gamma_{g b}^{0}=\left(E_{\text {slab }}^{g b}-E_{\text {slab }}^{f s}\right) / A
$$

where $E_{\text {slab }}^{g b}$ is the total energy of the supercell containing the GB and 2 FS (see Figure 2).

The strengthening energy $\eta_{i}$ is a quantity that characterizes the change of the work of separation into two FSs by changing the impurity excess from 0 to $\Gamma_{G B}$. Within the framework of the Rice-Wang theory [59], in the fast separation limit, it can be used to evaluate the propensity of a material toward brittle fracturing. Here, we adopt the following sign convention: a positive value of $\eta_{i}$ corresponds to GB embrittlement (reduction of work of separation) and a negative value to cohesive strengthening (increase in the work of separation). In the case wherein the same slab geometries are used in the calculations of the FS and GB, strengthening energy $\eta_{i}$ can be expressed as follows [58]:

$$
\eta_{i}=\frac{W_{s e p}^{0}-W_{s e p}^{i}}{\Gamma_{G B}}=E_{\text {trap }}^{g b}-E_{\text {trap }}^{f_{s}}
$$


where $W_{\text {sep }}^{i}, W_{\text {sep }}^{0}$ are the work of separation energies with and without $\mathrm{H} ; \Gamma_{G B}$ is the $\mathrm{H}$ excess; $E_{\text {seg }}^{g b}$ and $E_{\text {seg }}^{f s}$ are the $\mathrm{H}$ segregation energies of the GB and FS, respectively.

\subsection{Determination of H Concentration from Segregation Energies}

The interface trapping energies at $0 \mathrm{~K}$ described in the previous section can be directly used to estimate impurity concentration at the GB at $\mathrm{T}>0 \mathrm{~K}$ within the framework of the McLean-Langmuir isotherm assuming an ideal mixture of the solute and solvent atoms [60]:

$$
\frac{c_{k}}{1-c_{k}}=\frac{c_{0}}{1-c_{0}} \exp \left(-\frac{E_{\text {trap }}^{g b}(k)}{k_{B} T}\right)
$$

where $c_{k}$ is the occupancy of a GB site $k$ by solute atoms, $c_{0}$ is the site occupancy by solute atoms in the bulk, $k_{B}$ is the Boltzmann constant and $T$ is temperature.

The effective GB trapping energy can be written down as:

$$
E_{\text {trap }}^{g b}(k)=k_{B} T\left[\ln \left(\frac{c_{0}}{1-c_{0}}\right)-\ln \left(\frac{\left\langle c_{k}\right\rangle}{1-\left\langle c_{k}\right\rangle}\right)\right]
$$

where $\left\langle c_{k}\right\rangle=1 / N \sum_{k} c_{k}$ is averaged over $k$ trap sites within the trap width $\delta$ [25]; i.e., the spatial interval with no zero $E_{\text {trap }}^{g b}(k)$. Here we assume $\delta$ to be equal to the first 3 nearest neighbor distances from the defect. The corresponding effective solute concentration at the GB can be then expressed as:

$$
<c_{k}>=\frac{c_{0} \exp \left(-\frac{E_{\text {trap }}^{g b}(k)}{k_{B} T}\right)}{1-c_{0}+c_{0} \exp \left(-\frac{E_{\text {trap }}^{g b}(k)}{k_{B} T}\right)}
$$

The multi-site McLean-Langmuir isotherm used in this study accounts for configurational temperature effects only, while phonon and magnon contributions to the free energy of segregation are neglected. Since the temperatures of practical interest for the HE problem lay around and below the room temperature, we believe that this approximation represents a reasonable choice within this limit, as detailed phonon and magnon investigations for Fe-H system represent a formidable task at the moment and go beyond the scope of this paper.

\section{Results}

\subsection{Pure Fe}

\subsubsection{Bulk}

Ground State Properties of the Bulk Fe

The $0 \mathrm{~K}$ equilibrium lattice constant and the bulk modulus of ferromagnetic (FM) bcc Fe along with the spin magnetic moment are presented in Table 1 . The calculated lattice constant of $2.831 \AA$ is in good agreement with other DFT works [33,61-63]. This value underestimates the experimental value of $2.853 \AA$ extrapolated to $0 \mathrm{~K}$ [63]. This is a general result of DFT calculations of Fe and its alloys [64-68]. The calculated bulk modulus of 181 GPa agrees well with other DFT paper using the same exchange-correlation functional as used in this work [33,61,62] and slightly overestimates the low-temperature experimental value of $173 \mathrm{GPa}$ [69]. The calculated magnetic moment on Fe of $2.19 \mu_{\mathrm{B}}$ has also been found to agree well with reported in literature values of $2.20-2.33 \mu_{B}[33,61,62,70]$. 
Table 1. Lattice parameter (a) and bulk modulus (B) and magnetic moment ( $\mu$ ) of bcc Fe.

\begin{tabular}{cccc}
\hline Source & $\mathbf{a}, \AA$ & $\mathbf{B}, \mathbf{G P a}$ & $\mu, \mu_{\mathbf{B}}$ \\
\hline This work, PBE & 2.831 & 181 & 2.19 \\
\hline Material project DFT [61] & 2.847 & 182 & 2.33 \\
\hline Sanchez08 DFT, PBE [33] & 2.815 & 175 & 2.25 \\
\hline Hayward13 DFT,PBE [62] & 2.834 & 174 & 2.20 \\
\hline Rayne61 Exp. 3.2 K [69] & - & 173 & - \\
\hline Söderlind00 DFT [71] & 2.836 & 195 & - \\
\hline Haas09 DFT [63] & 2.833 & - & - \\
\hline Haas09 Exp. [63] & 2.853 & - &
\end{tabular}

Vacancy

Vacancies belong to one of the most common thermal defect types considered in the literature in relation to the problem of HE. They play an important role in diffusion processes in Fe [33,72,73] and in trapping of $\mathrm{H}$ atoms $[1,13]$. The formation energy of a vacancy in FM Fe at $0 \mathrm{~K}$ is shown in Table 2. Our value of $2.02 \mathrm{eV}$ falls in the midrange of DFT results available in literature $[18,72,74-79]$ and agrees well with the experimental data on the vacancy formation in the FM Fe [80]. The scatter in the DFT values is related to the pronounced dependence of the vacancy formation energy upon changes in the lattice parameter, the magnetic state (ferromagnetic/paramagnetic) and the exchange-correlation energy potential.

\section{Dislocation}

Dislocations are another important type of defect in iron, as they play a crucial role in plastic deformation processes in the material. Therefore, H-trapping at dislocations represents an important task for understanding the effect of $\mathrm{H}$ on the plasticity in iron and its alloys [81-85]. DFT modelling of dislocations is a very challenging and formidable task in many cases due to the physical dimensions of the defect $\left(10^{3}-10^{4}\right.$ atoms can be required to model such a defect). However, there are some methods that allow one to model dislocations of some special types [49-52,86]. In this work, we focus on two types of dislocations; namely, (i) $\frac{1}{2}<111>$ screw dislocation created using the periodic quadrupole arrangement [49], and for (ii) M111 mixed dislocation, a suitable periodic geometry was considered. The atomic structures of these dislocations after relaxation are shown in Figure 3. The [111] component of the relative displacement of the neighboring atoms produced by the dislocation is depicted as an arrow between them. The lengths of the arrows are proportional to the relative shifts of two neighbouring atoms along the surface normal, when inserting the dislocation in the perfect crystal. An arrow, connecting two neighbouring atoms, represents a shift of $1 / 3$ Burgers vectors [87]. The dislocation geometry is illustrated by a differential displacement map [88] in Figure 4a,b. The screw dislocation exhibits a compact core, as expected $[49,55,89,90]$. The M111 dislocations exhibits a planar core, as discussed in the seminal work by Vitek [88]. 

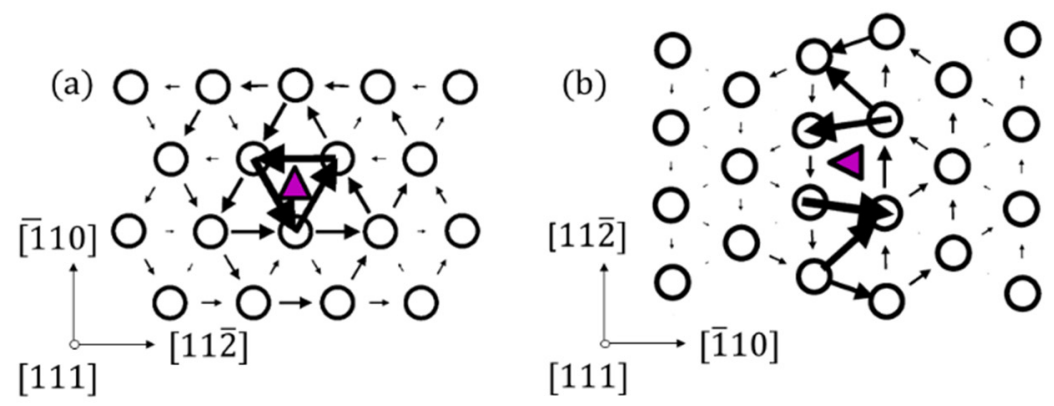

Figure 4. (a) $\frac{1}{2}<111>$ screw and (b) M111 mixed dislocations. The location of the dislocation core is marked as a purple triangle. The [111] (screw) component of the relative displacement of the neighboring atoms produced by the dislocation is depicted as an arrow between them.

Note that in contrast to the other defects, there is no characteristic defect energy that can be provided for the case of dislocations. This resides in the fact that the line energy diverges logarithmically, and therefore, the formation energy shows no convergence with the system size. The core energy, which would converge and could be obtained by subtracting the linear elastic energy, depends on the arbitrary choice of core radius and elastic constants, and hence, is also not characteristic for the dislocations.

\subsubsection{Interface}

\section{Grain Boundary and Free Surface}

Intergranular cleavage failure has been experimentally observed in various materials exposed to H-rich environments [91-93]. Therefore, GBs are often seen as one of the central microstructural elements in investigations of HE. In this work we consider three types of special CSL GBs: tilt $\Sigma 3(111)$ [1-10], tilt $\Sigma 5$ (012) [100] and twist $\Sigma 5$ (100) [001] GBs which upon brittle fracture cleave into (111) (021) and (100) FS respectively. The associated work of separation, and the formation energies of the aforementioned interfaces are presented in Table 2. Comparison of the calculated results to the analogous literature data yields good agreement between the current DFT $[64,80,94-97]$ results found in literature. The $\Sigma 3(111)$ [1-10], $\Sigma 5$ (012) [100] and $\Sigma 5$ (100) [001] GBs have GB energies of 1.60, 2.01 and $2.01 \mathrm{eV} /$ at, respectively.

Table 2. Formation energies of a vacancy; $\frac{1}{2}<111>$ screw and (b) M111 mixed dislocations; (111), (100) and (012) FS; $\Sigma 3$ (111) [1-10], $\Sigma 5$ (100) [100] and $\Sigma 5$ (012) [100] GBs and the corresponding $W_{\text {sep }}$ of bcc Fe. The results are compared to the available theoretical $[4,18,72,74-79,98-103]$ and experimental [64,80,94-97,104,105] data.

\begin{tabular}{|c|c|c|c|c|}
\hline Characteristic & Defect Type & This Work & DFT Studies & Experimental \\
\hline Formation energy, e & Vacancy & 2.02 & $\begin{array}{c}1.93,1.95,2.01[72], 1.86,2.06 \\
2.16[75] \\
2.14[76], 2.15[73,74,77], 2.17 \\
{[77,78],} \\
2.37[18], 2.39[79]\end{array}$ & $\begin{array}{c}1.4[94], 1.5[95], \\
1.6[96], \\
1.61-1.75[97], 1.7[64], \\
2.00[80]\end{array}$ \\
\hline \multirow[t]{3}{*}{ FS energy, $\mathrm{J} / \mathrm{m}^{2}$} & (111) FS & 2.67 & $\begin{array}{c}2.52[106], 2.69[4], 2.69[98], \\
2.65[74], 2.71,3.23[103]\end{array}$ & \multirow[t]{3}{*}{$\begin{array}{l}2.42[104], \\
2.48[105]\end{array}$} \\
\hline & (012) FS & 2.44 & & \\
\hline & (100) FS & 2.94 & $2.55,3.06$ [103], 2.29 [106] & \\
\hline
\end{tabular}


Table 2. Cont.

\begin{tabular}{|c|c|c|c|c|}
\hline Characteristic & Defect Type & This Work & DFT Studies & Experimental \\
\hline \multirow[t]{3}{*}{ GB energy, $\mathrm{J} / \mathrm{m}^{2}$} & $\begin{array}{c}\sum 3(111) \\
{[1-10]} \\
\text { GB }\end{array}$ & 1.60 & $\begin{array}{c}1.57[102], 1.52[4], 1.66[74] \\
1.46[100], 1.61[99], 1.57[101], \\
1.79[103]\end{array}$ & - \\
\hline & $\begin{array}{c}\Sigma 5(012) \\
{[100]}\end{array}$ & 1.60 & $2.00[102], 1.64[101], 1.83[13]$ & - \\
\hline & $\begin{array}{c}\Sigma 5(100) \\
{[001]}\end{array}$ & 2.01 & 2.12 [101], 2.20 [103] & - \\
\hline \multirow[t]{3}{*}{ Work of separation, $\mathrm{J} / \mathrm{m}^{2}$} & $\begin{array}{c}\Sigma 3(111) \\
{[1-10]}\end{array}$ & 3.76 & $\begin{array}{c}3.86[4], 3.65[74] \\
3.78[102], 4.60[103]\end{array}$ & - \\
\hline & $\Sigma 5(012)[100]$ & 2.88 & 3.19 [102] & - \\
\hline & $\Sigma 5(100)[001]$ & 3.86 & $3.90[103]$ & - \\
\hline
\end{tabular}

\subsection{Iron + Hydrogen}

\subsubsection{Hydrogen Trapping in the Bulk}

Hydrogen Solubility in Fe Lattice

We have considered three possible sites for $\mathrm{H}$ dissolution in the Fe lattice: (i) the tetrahedral interstitial, (ii) the octahedral interstitial and (iii) the substitutional site. In agreement with literature data $[62,78,79,107,108]$, our calculations show that the most favourable site for $\mathrm{H}$ in bcc Fe lattice is the interstitial tetrahedral with a formation energy of $0.23 \mathrm{eV}$. With the chosen plane-wave cutoff and k-point sampling, the reported formation energies are estimated to be converged. The interstitial octahedral and the substitutional sites have higher formation energies of 0.37 and $2.54 \mathrm{eV}$, respectively (see Table 3). These results have been obtained using the largest supercell (SC) of 128 atoms considered in this work. However, as it has been shown in reference [109], the formation energies of point defects may have a very slow convergence with respect to the supercell size, and therefore an extrapolation may be required to get an accurate value of the formation energy in the dilute limit. Following the methodology of reference [109], we have calculated the solution energy of $\mathrm{H}$ at the most stable interstitial tetrahedral position as a function of the supercell size $\mathrm{N}$ at the constant $0 \mathrm{~K}$ equilibrium volume of bcc Fe (allowing only for relaxation of the atomic positions) and at constant zero pressure (allowing for the complete relaxation of the atomic positions, SC shape and volume). In the limit of $1 / \mathrm{N} \rightarrow 0$ (infinitely large SC), these two quantities converge to a single value [11] corresponding to the "true" dilute limit.

Table 3. Solution energies of $\mathrm{H}$ in pure Fe. The results are compared to the available theoretical $[62,78,79,107,108]$ and experimental [110-112] data. The experimental data extrapolated to $0 \mathrm{~K}$ with ZPE [62] excluded are shown in parenthesis.

\begin{tabular}{cccc}
\hline \multirow{2}{*}{ Type of H Site } & \multicolumn{3}{c}{ Solution Energy, eV } \\
\cline { 2 - 4 } & This Work & Theoretical & Experimental \\
\hline Interstitital tetrahedral & $0.23(4 \times 4 \times 4$ cell $)$ & $0.19[107], 0.21[78], 0.23$ & $0.30(0.20)[110,111], 0.28$ \\
& $0.22($ dilute limit $)$ & {$[62], 0.27[79]$} & $(0.18)[112]$ \\
\hline Interstitital octahedral & $0.37(4 \times 4 \times 4$ cell $)$ & $0.26[62], 0.32[107], 0.34$ & - \\
& & {$[78], 0.35[79]$} & - \\
\hline substitutional & $2.54(4 \times 4 \times 4$ cell) & $2.53[108], 2.61[78]$ & \\
\hline
\end{tabular}

Our results demonstrate this type of behaviour resulting in single value of the solution energy of $\mathrm{H}$ of $0.22 \mathrm{eV}$. The results are shown in Figure 4. A direct comparison of the present DFT $0 \mathrm{~K}$ results to the available experimental ones $[107,110-112]$ requires a correction to the zero point vibrational 
energy (ZPE) that has been calculated to be equal to $0.10 \mathrm{eV}$ (in the case of tetrahedral site TS of H) [62]. The ZPE-corrected experimental data (shown in Figure 5) were found to be in very good agreement with the present DFT results.

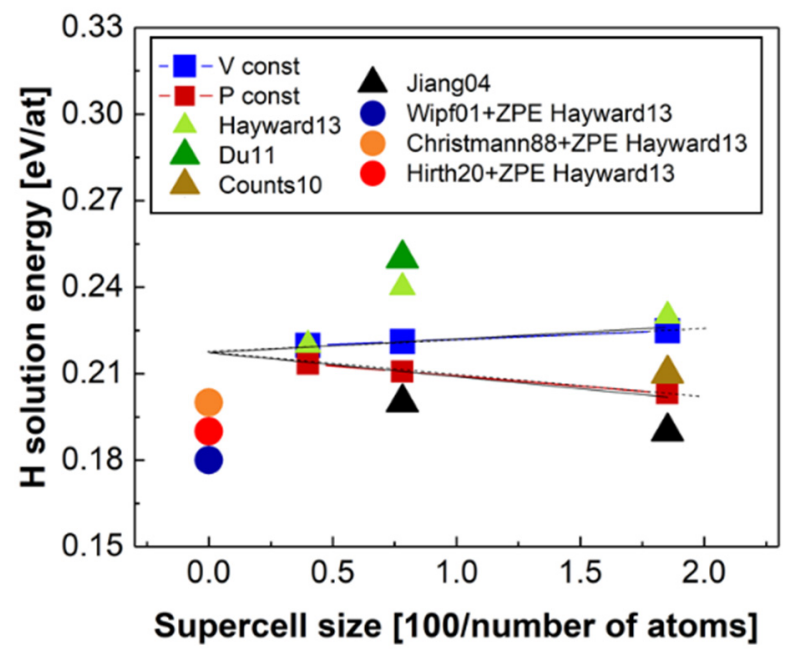

Figure 5. Dependence of the TS-H-interstitial formation energy on the supercell size at constant volume (blue line, blue squares) and at constant pressure (red line, red squares). The results of the present calculations are compared to other theoretical $[62,78,107,113]$ data marked as triangles and experimental data extrapolated to $0 \mathrm{~K}$ (ZPE corrected) [110-112] and marked as circles.

Hydrogen Trapping at A Vacancy

Hydrogen trapping at a vacancy has drawn a lot of attention in the literature $[12,24,74,114]$. It is known that there are six potential octahedral, interstitial trapping sites for $\mathrm{H}$ adjacent to the vacancy [24]. In references [18,24], it was found that $\mathrm{H}$ may form a stable complex with a vacancy in Fe consisting of two $\mathrm{H}$ and one vacancy. Here, we focus on the lowest energy cluster configurations found in reference [12] $(1 \mathrm{H}-\mathrm{V}, 2 \mathrm{H}-\mathrm{V}$ and $3 \mathrm{H}-\mathrm{V})$. The results presented in Figure 6 and Table 4 confirm that the $2 \mathrm{H}-\mathrm{V}$ cluster has the lowest trapping energy equal to $-0.63 \mathrm{eV} /$ at, stronger than the -0.61 value $[12,24,114]$ found in other works. The results also show that there is a strong H-vacancy attractive interaction for $\mathrm{nH}$-vacancy clusters with $\mathrm{n}<6$. The most stable $2 \mathrm{H}$-vacancy cluster has a trapping energy of $-58 \mathrm{eV} / \mathrm{at}$, which is close to the $1 \mathrm{H}-\mathrm{V}$ complex, whereas all other complexes have substantially higher trapping energies. Addition of the ZPE correction to the trapping energies based on available literature data reduces the trapping energies by about $0.11 \mathrm{eV}$ [62] for $1 \mathrm{H}-\mathrm{V}, 2 \mathrm{H}-\mathrm{V}$ complexes and by $0.04 \mathrm{eV}$ [62] for 3H-V (see Figure 6).

The experimental results on deuterium trapping reported in references $[115,116]$ suggest that there are two sorts of -0.48 and $-0.63 \mathrm{eV}$ trapping energies associated with H-trapping at vacancies. In reference [115], the lowest energy trap $-0.63 \mathrm{eV}$ has been associated with the $1 \mathrm{H}-\mathrm{V}, 2 \mathrm{H}-\mathrm{V}$ defect complexes, whereas the other trapping energy of $-0.48 \mathrm{eV}$ has been related with the (3-6) $\mathrm{H}-\mathrm{V}$ complexes based on the conclusions drawn from the effective-medium theory calculations [115]. The results of the effective-medium theory calculations [115] are available relative to $1 \mathrm{H}-\mathrm{V}$ cluster only, and are therefore shown relative to the lowest experimental trapping energy of $-0.63 \mathrm{eV}$ in Figure 6 , as in the original paper [115]. This interpretation of the experimental data agrees in general with our results and the theoretical literature data presented in Table 4 . And Figure 7 shows hydrogen trapping profiles for $\Sigma 3$ (111) GB, (111) FS, mixed 111 dislocation and a vacancy. 
(a)

(b)

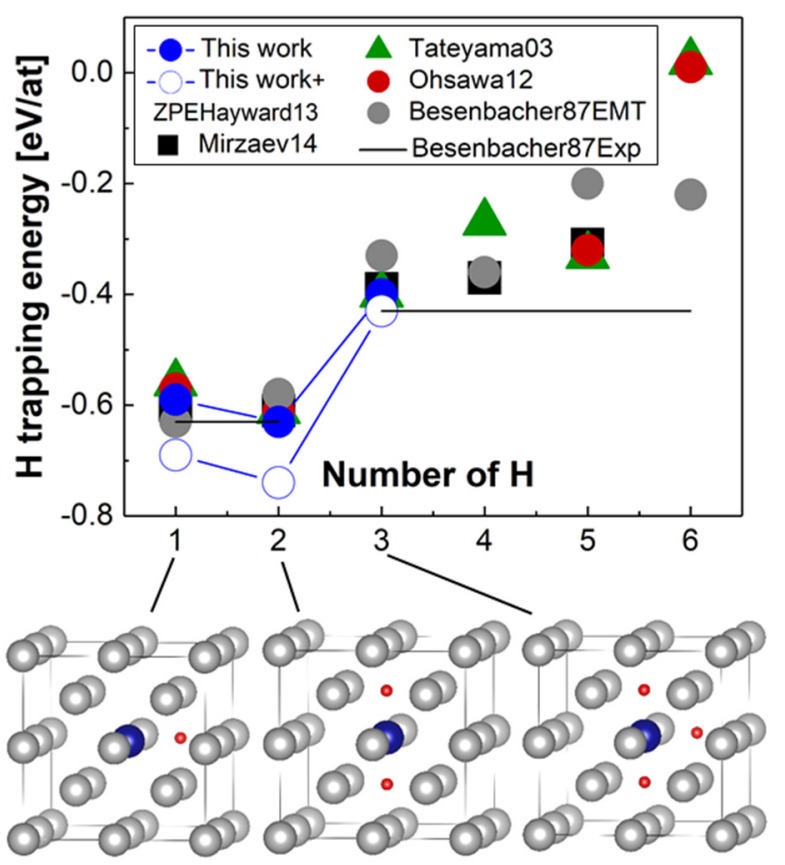

Figure 6. (a) Dependence of the H-trapping energy on the number of $\mathrm{H}$ atoms $(n)$ in the $n \mathrm{H}-\mathrm{V}$ cluster. The results of the present calculations are compared to other theoretical data $[12,24,114]$ and experimental results $[115,116]$. (b) Structures of H-vacancy clusters are shown in the bottom panel. The vacancy is marked as a blue circle. Hydrogen atoms are shown with small red circles.

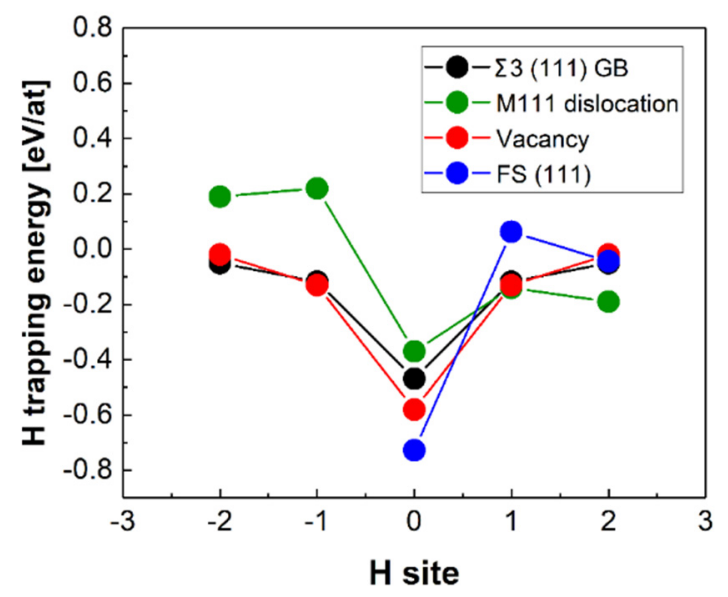

Figure 7. Hydrogen trapping profiles for $\Sigma 3$ (111) GB, (111) FS, mixed 111 dislocation and a vacancy. The trapping energies are presented relative to the geometrical centre of each defect indicated by 0 . The considered trapping sites are located at the first, second and third atomic planes away from the corresponding defects, as indicated in Figures $2 \mathrm{a}$ and $3 \mathrm{~b}$. In the case of a vacancy, the next nearest neighbour TS positions are shown. Minus signs refer either to mirrored or to compressed (in the case of M111 dislocation) crystallographic directions. 
Table 4. H-trapping energies in Fe (in eV/at). Literature data $[12-18,23,27]$ and the results of this work. Zero point energy correction added to the $0 \mathrm{~K}$ results has been taken from references $[17,27,62]$, and it is shown in the parentheses.

\begin{tabular}{|c|c|c|c|c|c|c|}
\hline Type of Defect & $\begin{array}{l}\text { Literature } \\
\text { Data at } 0 \mathrm{~K}\end{array}$ & $\begin{array}{c}\text { Literature Data } \\
\text { at } 0 \mathrm{~K}+\mathrm{ZPE} \\
(\text { Defect +H) }\end{array}$ & Method & This Work & $\begin{array}{c}\text { This Work + } \\
\text { ZPE }\end{array}$ & $\begin{array}{c}\text { Experimental } \\
\text { Data }\end{array}$ \\
\hline Vacancy & & & DFT, PBE & & & \\
\hline H1V & $\begin{array}{c}-0.69 \text { [117], } \\
-0.57 \text { [114], } \\
-0.6[12], \\
-0.5[62]\end{array}$ & $\begin{array}{l}-0.56[24] \\
-0.62[62]\end{array}$ & \multirow[t]{6}{*}{$\begin{array}{c}\text { DFT PW91 [12] } \\
\text { DFT PBE } \\
{[13,14,22,57,104]}\end{array}$} & -0.58 & $\begin{array}{c}-0.70(-0.12) \\
{[62]}\end{array}$ & \multirow[t]{2}{*}{$-0.63[115]$} \\
\hline $\mathrm{H} 2 \mathrm{~V}$ & $\begin{array}{c}-0.61 \\
{[12,24,114],} \\
-0.54[62]\end{array}$ & $-0.65[62]$ & & -0.63 & $\begin{array}{c}-0.74(-0.11) \\
{[62]}\end{array}$ & \\
\hline $\mathrm{H} 3 \mathrm{~V}$ & $\begin{array}{c}-0.40 \\
{[24,114]} \\
-0.39 \\
{[12],-0.34} \\
{[62]}\end{array}$ & -0.38 [62] & & -0.39 & $\begin{array}{c}-0.43(-0.04) \\
{[62]}\end{array}$ & \multirow[t]{4}{*}{$-0.43[115]$} \\
\hline $\mathrm{H} 4 \mathrm{~V}$ & $\begin{array}{c}-0.27[24], \\
-0.36[114], \\
-0.37[12] \\
-0.30[62]\end{array}$ & $-0.35[62]$ & & & & \\
\hline $\mathrm{H} 5 \mathrm{~V}$ & $\begin{array}{l}-0.33[24], \\
-0.32[114], \\
-0.31[12] \\
-0.27[62]\end{array}$ & $-0.27[62]$ & & & & \\
\hline $\mathrm{H} 6 \mathrm{~V}$ & $\begin{array}{c}0.02[24], \\
0.01[114], \\
0.043[62]\end{array}$ & $-0.045[62]$ & & & & \\
\hline \multicolumn{7}{|l|}{ GB } \\
\hline Tilt $\Sigma 3$ (111) & -0.39 [107] & -0.58 [27] & \multirow[t]{11}{*}{ DFT PBE } & -0.47 & $\begin{array}{c}-0.57(-0.1) \\
{[27]}\end{array}$ & \multirow{11}{*}{$\begin{array}{l}-0.18[118] \\
-0.28[119] \\
-0.61[120]\end{array}$} \\
\hline Tilt $\Sigma 5$ (012) & $-0.81[107]$ & & & -0.42 & & \\
\hline Tilt $\Sigma 5$ (013) & $-0.43[107]$ & & & & & \\
\hline Tilt $\Sigma 9(1 / 211)$ & $-0.29[15]$ & & & & & \\
\hline Tilt $\Sigma 13(1 / 311)$ & $-0.27[15]$ & & & & & \\
\hline Tilt $\Sigma 17$ (1/4 11) & $-0.32[15]$ & & & & & \\
\hline Twist $\Sigma 3(110)$ & $-0.26[17]$ & & & & & \\
\hline Twist $\Sigma 5$ (100) & - & & & -0.57 & & \\
\hline Twist $\Sigma 9(110)$ & $-0.68[17]$ & & & & & \\
\hline Twist $\Sigma 11(110)$ & -0.83 [17] & & & & & \\
\hline Twist $\Sigma 17(110)$ & $-0.95[17]$ & & & & & \\
\hline \multicolumn{7}{|l|}{ Dislocation } \\
\hline Edge & $-0.47[16]$ & & $\mathrm{QM} / \mathrm{MM}$ & & & \multirow{3}{*}{$\begin{array}{l}-0.28[118] \\
-0.20[121] \\
-0.31[122] \\
-0.25[123]\end{array}$} \\
\hline Screw $1 / 2<111>$ & $\begin{array}{c}-0.27[19,20] \\
0.2 \text { to }-0.3 \\
{[124]} \\
-0.26[23]\end{array}$ & $-0.32[17]$ & $\begin{array}{c}\text { QM/MM [19], } \\
\text { DFT, PBE } \\
\text { [20,125], } \\
\text { MD[23] }\end{array}$ & -0.21 & $\begin{array}{c}-0.26(-0.05 \\
[17])\end{array}$ & \\
\hline Mixed <111> & $\sim-0.3$ [124] & - & DFT PBE & -0.37 & & \\
\hline
\end{tabular}

Hydrogen Trapping at a Dislocation

Two types of dislocations, the $\frac{1}{2}<111>$ screw and the M111 mixed have been considered for $\mathrm{H}$-trapping in Fe. Hydrogen segregates to dislocation core structure in the case of both considered dislocations. In addition to the displacement related to the dislocation core insertion to the bcc $\mathrm{Fe}$ 
lattice, shown in Figure 4, larger displacements appear near to the $\mathrm{H}$ location in cases of the screw and mixed dislocations (see Figure 8).

(a)

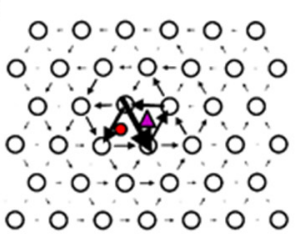

(d)

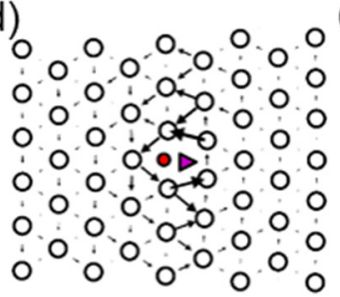

(b)

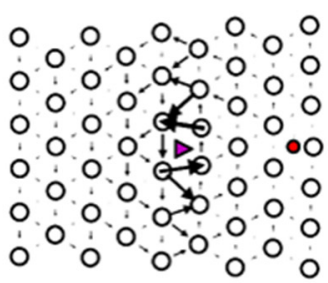

(e)

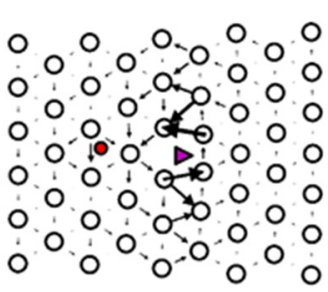

(c)

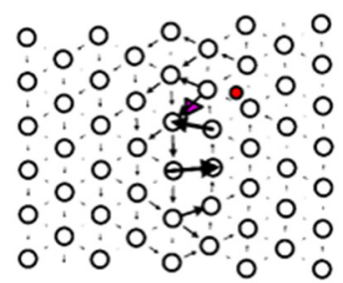

(f)

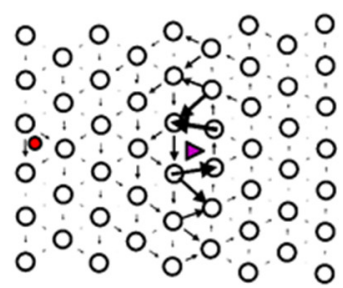

Figure 8. The locations of $\mathrm{H}$ sites (a) in the computational cell with two $\frac{1}{2}<111>$ screw dislocations, $(\mathbf{b}-\mathbf{f})$ corresponding to the sites from -2 to 2 from Figure $3 \mathrm{~b}$ in the cell with two mixed 111 dislocations. The location of the dislocation core is marked as a purple triangle; the final positions of $\mathrm{H}$ after the optimisation are shown as the red circles. The [111] component of the relative displacement of the neighboring atoms produced by the dislocation is depicted as an arrow between them.

The hydrogen atom has been inserted in the cell with the screw dislocation, as illustrated in Figure 3a. The corresponding minimal segregation energy is listed in Table 4. In agreement with reference [17] the energetically most favourable position has been found to be located in the three corners of the screw dislocation core, as shown in Figure 3a. It should be noticed that the displacements are significantly amplified next to the $\mathrm{H}$ atom, which illustrates attractive interactions between $\mathrm{H}$ and the dislocation.

In the case of the M111 dislocation, $\mathrm{H}$ was placed at several positions in the core according to Figure $8 \mathbf{b}-\mathrm{f}$. The hydrogen was moved normal to the glide plane, as this does not induce dislocation glide. Attempts were made to place the $\mathrm{H}$ atoms on the glide plane too, at some distance from the dislocation. In this case, the dislocation followed the $\mathrm{H}$ atom, indicating that the positive attraction is strong enough to overcome the Peierls barrier. In what follows, these positions were not taken into account. The segregation energies are provided in Table 4. In Figure 8, the relaxed geometries with the $\mathrm{H}$ atom in positions 0 and 1 are shown. In these cases, $\mathrm{H}$ breaks the symmetry of the core structure. The displacements were amplified next to the $\mathrm{H}$ atom in agreement with the observation for the screw dislocation of an attractive interaction. The strongest segregation site was located close to the centre of the dislocation but not exactly in the middle. Similarly to the screw dislocation and the vacancy, the energetically most favourable position was not in the centre of the dislocation. In general, segregation energies are lower for the M111 dislocations compared to the screw dislocations. It should be taken into account that the segregation energy profile at the M111 dislocation core is not symmetric, i.e., site -2 is not equal to site 2 (see Figure $3 b$ ), since the lattice is compressed for negative segregation site indices and expanded for positive segregation site indices (Figure 9). This reveals that the solubility increases in expanded regions and decreases in compressed regions (Figure $3 b$ ), as one would intuitively expect. 

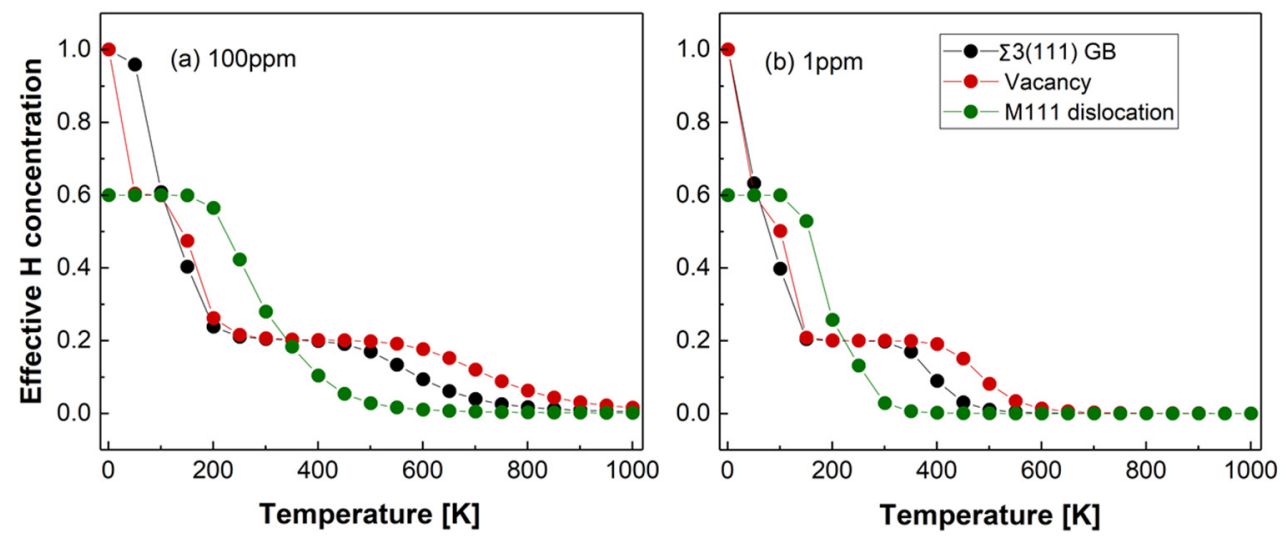

Figure 9. The temperature dependence of the H concentration at $\Sigma 3$ (111) GB, M111 dislocation and a vacancy (a) for $\mathrm{H}$ bulk concentration 100 ppm, (b) for $\mathrm{H}$ bulk concentration 1 ppm.

The sites with the minimum trapping energies of -0.21 and $-0.37 \mathrm{eV}$ are found for $\mathrm{H}$ located at the corner of the dislocation core for the $\frac{1}{2}<111>$ screw and near to the centre of the dislocation core (marked with triangle in Figure 8) for the M111 mixed dislocations, respectively. As one can see in Figures 7 and 8, $\mathrm{H}$ is repelled from the "compressed" region near the M111 mixed dislocation core and attracted to the "expanded" one. In the case of the screw dislocation, the trapping energies of the corner geometries (see Figure 3) have similar values of $-0.21 \mathrm{eV}$ and are in good agreement with the results of Itakura [17] (see Table 4).

\subsubsection{Interfaces}

\section{Hydrogen Trapping at GB}

We have considered several possible sites for H-trapping in the GB planes of three special CSL GBs-CSL $\Sigma 3$ (111) [1-10], $\Sigma 5$ (012) [100] and $\Sigma 5$ (100) [001] GBs—as shown in Figure 2. In the case of $\Sigma 3 \mathrm{~GB}$, six equivalent positions of $\mathrm{H}$ (see Figure 2a) refer to octahedral site OS in the original bcc lattice and correspond to the strongest $\mathrm{H}$-trapping energies $\left(E_{\text {trap }}^{g b}=-0.48 \mathrm{eV}\right)$. This result has been found to be in good agreement with the literature $[10,13,27,125]$. The hydrogen atoms in the t position located in the first layer after the GB plane are not stable and relax to the OS positions $\left(E_{\text {trap }}^{g b}=-0.36 \mathrm{eV}\right)$. The hydrogen atom placed in $\mathrm{t}$ position (see the Figure 2a), corresponding to TS in the original bcc lattice, is located in the next layer after $\Sigma 3 \mathrm{~GB}$ plane layers $\left(E_{\text {trap }}^{g b}=-0.12 \mathrm{eV}\right)$.

In the case of $\Sigma 5$ (012) [100], four inequivalent positions of $\mathrm{H}$ in the GB plane have been considered (see Figure 2b) using the Voronoi tessellation [125] for the identification of possible segregation sites. The lowest trapping energy belongs to the $4 \mathrm{i}$ site $\left(E_{\text {trap }}^{g b}-0.42 \mathrm{eV}\right)$, while others have the trapping energies from -0.34 to $-0.37 \mathrm{eV}$.

For the twist $\Sigma 5$ (100) [100] GB, nine inequivalent positions of $\mathrm{H}$ within \pm 6 Angstrom from the GB layer are found, using the Voronoi tessellation [125]. The strongest trapping energy of $\mathrm{H}$ has been found at site 1i shown in Figure 2c.

In the case of $\mathrm{H}$-trapping at $\Sigma 3$ (111) [1-10] GB, we have additionally considered the possibility of $\mathrm{H}$ atoms segregating off the GB plane. We have considered the same lowest energy trapping site for the near GB layers as $3 t$ site (see the Figure 2a) in all calculations. The calculations (see Figure 7) have shown that the lowest energy site located beyond the GB plane has always been the $3 t$ site, as shown in Figure 2a.

Effect of $\mathrm{H}$ on the Bulk and GB Cohesion

Hydrogen presence in the lattice can deteriorate the interatomic bonding in the crystal. Here, we use the partial cohesive energy $(\mathrm{X})$ concept [56] to evaluate the influence of $\mathrm{H}$ on the cohesive strength 
in the bulk of Fe. The results of our DFT calculations, shown in Table 5, provide us with a negative value of $\chi$ of $-3.34 \mathrm{eV} / \mathrm{at}$, indicating that $\mathrm{H}$ will deteriorate the interatomic bonding in the Fe lattice and reduce its resistance to decohesion.

Table 5. Partial cohesive energy and strengthening energies, given in eV/at.

\begin{tabular}{ccc}
\hline Characteristic & This Work & Literature \\
\hline$\chi$ bulk & -3.34 & - \\
$\eta \Sigma 3(111)[1-10]$ & 0.26 & $0.26-0.41[10,13,27,125]$ \\
$\eta \Sigma 5(012)[100]$ & 0.41 & $0.07[13]$ \\
$\eta \Sigma 5(100)[001]$ & 0.05 & - \\
\hline
\end{tabular}

We have investigated the effect of H-trapping on the GB cohesive strength in Fe using the strengthening energy $\eta$. For that purpose, H-trapping at FS in Fe in the positions shown in Figure 2 has been calculated as well (H sites at (111), (012), (001) FS correspond to 3t, $4 \mathrm{i}$ and from $1 \mathrm{i}$ positions from Figure $2 \mathrm{a}-\mathrm{c}$ ). The results of the H-trapping profile calculations at $\Sigma 3$ (111) GB (Figure 7) have shown that the most favorable among considered for segregation sites is located within the interface plane. In the case of all (111), (012) and (001) FS created by cleavage of $\Sigma 3$ (111) [1-10], $\Sigma 5$ (012) [100] and $\Sigma 5$ (100) [001] GBs respectively, we have used the in-plane FS sites to calculate the strengthening energy $\eta$. As one can see from the results shown in Table 5, H embrittles all GBs and has the $\eta$ values varying from 0.05 ( $\Sigma 5(100)[001])$ to $0.41 \mathrm{eV}(\Sigma 5(012)[100])$.

\section{Discussion}

\subsection{Trap Hierarchy at $0 \mathrm{~K}$}

Comparison of the H-trapping energies at $0 \mathrm{~K}$ presented in Table 2 allows us to split the traps into two groups: (i) vacancies and GBs with the associated trapping energies varying from -0.39 to $-0.63 \mathrm{eV}$ and (ii) dislocations with the trapping energies $<-0.37 \mathrm{eV}$. Our results show that H-trapping at the considered defects is described by a distribution of trapping energies shown in Figure 6 rather than by single trapping energy values used in most of the works on H-trapping so far [13,14,16-18]. The absolute lowest trapping energy of $-0.63 \mathrm{eV}$ has been found for the case of the vacancy-2H cluster. This trapping energy is followed by the H-trapping energy at the $\Sigma 5$ (100) twist GB, which is only $0.06 \mathrm{eV}$ higher. Following the results of reference [14], we are prone to think that twist GBs with higher $\Sigma$ values (mostly not feasible for DFT investigations) could exhibit even lower trapping energies, which makes GB virtually equivalent to vacancy traps in Fe. Therefore, we have assigned GBs and vacancies to one group of defects with very similar trapping energies for $\mathrm{H}$ atoms, which could be indistinguishable in experiments. In general, $\mathrm{H}$ is found to be trapped at all considered types of defects and to have a negative effect on the cohesive strength of interatomic bonding in both bulk and interfaces.

\subsection{Traps at Finite Temperatures}

The effective $H$ concentration at the vacancy, M111 dislocation and $\Sigma 3$ (111) GB determined using Equation (13) is shown in Figure 9. Here, we have assumed 100 at ppm (a) in Figure 9 and 1 at ppm (b) in Figure 9. H content in the bulk of Fe $[25,26,126,127]$ and the $0 \mathrm{~K} \mathrm{H}$-trapping profiles are shown in Figure 7.

The results of the McLean-Langmuir segregation isotherm at 100 at ppm $\mathrm{H}$ in the bulk of Fe suggest that $\mathrm{H}$ predominantly occupies GB and vacancies at low temperatures $(<100 \mathrm{~K})$. In the temperature interval from 100 to $400 \mathrm{~K}, \mathrm{H}$ concentration at all considered defects is virtually the same with a slight preference to the M111 dislocation, whereas most Hs are accumulated at vacancies at $\mathrm{T}>400 \mathrm{~K}$ followed by the GB and dislocations. At the room temperature $+/-100 \mathrm{~K}$ (approximately 200-400 K), H concentration at dislocations shows a much faster decreasing tendency (at both 1 and 
$100 \mathrm{ppm} \mathrm{H}$ in the bulk), while $\mathrm{H}$ concentration at vacancies and GBs remains basically unchanged. It is related to the different shape of the $\mathrm{H}$-trapping profile for the dislocation in comparison to $\mathrm{H}$-trapping profiles at the GB and vacancy shown in Figure 7. This result indicates that H-trapping at the M111 type of dislocations can be more sensitive to the bulk $\mathrm{H}$ concentration and temperature changes than trapping at GBs and vacancies, which is an important aspect of the HELP mechanism of HE.

The overall amount of $\mathrm{H}$ in the system dramatically drops as temperature increases. Concentration of $\mathrm{H}$ at almost all defects decreases by a factor of 5 (GB and vacancy) or 3 (dislocation) as the temperature increases from 0 to $400 \mathrm{~K}$. At 1 at ppm $\mathrm{H}$ in the bulk of Fe the $\mathrm{H}$ concentration at dislocation has significantly dropped but it has remained at about the same level as it was for GB and vacancy, assuming infinitely large grains and the amount of vacancies proportional to the concentration of $\mathrm{H}$. These results show that $\mathrm{H}$ can be evenly distributed between different defects at the room temperature $+/-100 \mathrm{~K}$. This would also mean that the effective H-trapping energies at vacancies, GBs or dislocations can be virtually indistinguishable from one another and the interpretation of some experimental and theoretical results in terms of preferred trapping sites should be done with extra caution.

\section{Conclusions}

Hydrogen trapping in the bulk lattice and at all typical defects in bcc Fe has been systematically investigated by means of the same methodology of DFT calculations at $0 \mathrm{~K}$. The results show that $\mathrm{H}$ occupies the tetrahedral interstitial site in the bulk lattice and prefers trapping at GB and vacancies to trapping at screw and mixed dislocations at $0 \mathrm{~K}$. The mixed dislocation has been found to be a more attractive trap for $\mathrm{H}$ in $\mathrm{Fe}$ than the screw. Our results also show that trapping energies at each defect represent a distribution of trapping energies rather than a single trapping energy value.

We have used these unique sets of trapping energy distributions to evaluate $\mathrm{H}$ concentration at all considered defects at finite temperatures using the McLean-Langmuir segregation isotherm. The results of the segregation isotherm modeling using DFT trapping energy profiles suggest that all considered defects may have virtually the same amount of trapped $\mathrm{H}$ atoms at about room temperature $+/-100 \mathrm{~K}$, and therefore are equally important for addressing the problem of $\mathrm{HE}$ in Fe. This result also indicates that a special care has to be taken for interpretation of experimental data on H-trapping at room temperatures using DFT results obtained at $0 \mathrm{~K}$. DFT calculations of the partial cohesive and the GB strengthening energies suggest that $\mathrm{H}$ will have a negative effect on the cohesive strength of interatomic bonding in both bulk and at the interfaces in bcc Fe.

Author Contributions: Conceptualization, V.I.R. and A.S.K.; methodology, V.I.R., L.R. and D.S.; validation, V.I.R., L.R. and W.E.; formal analysis, A.S.K, V.I.R. and L.R.; investigation, A.S.K.; data curation, A.S.K.; writing-original draft preparation, A.S.K.; writing-review and editing, V.I.R., L.R., R.P., W.E. and D.S.; visualization, A.S.K.; supervision, R.P. and V.I.R..; project administration, W.E.; funding acquisition, W.E. All authors have read and agreed to the published version of the manuscript.

Funding: This research was funded by the COMET program within the K2 Center Integrated Computational Material, Process and Product Engineering (IC-MPPE), project number 859480. This program is supported by voestalpine Tubulars $\mathrm{GmbH}$, voestalpine Stahl Donawitz $\mathrm{GmbH}$, Robert Bosch $\mathrm{GmbH}$, the Austrian Federal Ministries for Transport, Innovation and Technology (BMVIT) and for Digital and Economic Affairs (BMDW), represented by the Austrian research funding association (FFG), and the federal states of Styria, Upper Austria and Tyrol.

Acknowledgments: All calculations in this work have been done using Vienna Scientific Cluster (VSC-3). In addition, the authors wish to thank Matous Mrovec for the fruitful discussion on the GB part of the paper.

Conflicts of Interest: The authors declare no conflict of interest. The funders had no role in the design of the study; in the collection, analyses, or interpretation of data; in the writing of the manuscript or in the decision to publish the results.

\section{References}

1. Nagumo, M. Fundamentals of Hydrogen Embrittlement; Springer: Singapore, 2016; ISBN 9789811001611.

2. Bhadeshia, H.K.D.H. Prevention of hydrogen embrittlement in steels. ISIJ Int. 2016, 56, 24-36. [CrossRef] 
3. Robertson, I.M.; Sofronis, P.; Nagao, A.; Martin, M.L.; Wang, S.; Gross, D.W.; Nygren, K.E. Hydrogen embrittlement understood. Metall. Mater. Trans. A Phys. Metall. Mater. Sci. 2015, 46, 2323-2341. [CrossRef]

4. Yamaguchi, M.; Kameda, J.; Ebihara, K.-I.; Itakura, M.; Kaburaki, H. Mobile effect of hydrogen on intergranular decohesion of iron: First-principles calculations. Philos. Mag. 2012, 92, 1349-1368. [CrossRef]

5. Hickel, T.; Nazarov, R.; McEniry, E.J.; Leyson, G.; Grabowski, B.; Neugebauer, J. Ab initio based understanding of the segregation and diffusion mechanisms of hydrogen in steels. Jom 2014, 66, 1399-1405. [CrossRef]

6. Geng, W.-T.; Freeman, A.J.; Olson, G.B.; Tateyama, Y.; Ohno, T. Hydrogen-promoted grain boundary embrittlement and vacancy activity in metals: Insights from ab initio total energy calculatons. Mater. Trans. 2005, 46, 756-760. [CrossRef]

7. Pérez Escobar, D.; Depover, T.; Duprez, L.; Verbeken, K.; Verhaege, M. Combined thermal desorption spectroscopy, differential scanning calorimetry, scanning electron microscopy and X-ray diffraction study of hydrogen trapping in cold deformed TRIP steel. Acta Mater. 2012, 60, 2593-2605. [CrossRef]

8. Pérez Escobar, D.; Duprez, L.; Atrens, A.; Verbeken, K. Influence of experimental parameters on thermal desorption spectroscopy measurements during evaluation of hydrogen trapping. J. Nucl. Mater. 2014, 450, 32-41. [CrossRef]

9. Geng, W.T.; Freeman, A.J. Embrittling and strengthening effects of hydrogen, boron, and phosphorus on a $\Sigma$ 5 nickel grain boundary. Phys. Rev. B 1999, 60, 7149-7155. [CrossRef]

10. Zhong, L.; Wu, R.; Freeman, A.J.; Olson, G.B. Charge transfer mechanism of hydrogen-induced intergranular embrittlement of iron. Phys. Rev. B Condens. Matter Mater. Phys. 2000, 62, 13938-13941. [CrossRef]

11. Mishin, Y.; Asta, M.; Li, J. Atomistic modeling of interfaces and their impact on microstructure and properties. Acta Mater. 2010, 58, 1117-1151. [CrossRef]

12. Mirzaev, D.A.; Mirzoev, A.A.; Okishev, K.Y.; Verkhovykh, A.V. Hydrogen-vacancy interaction in bcc iron: $\mathrm{Ab}$ initio calculations and thermodynamics. Mol. Phys. 2014, 112, 1745-1754. [CrossRef]

13. Mirzaev, D.A.; Mirzoev, A.A.; Okishev, K.Y.; Verkhovykh, A.V. Ab initio modelling of the interaction of $\mathrm{H}$ interstitials with grain boundaries in bcc Fe. Mol. Phys. 2016, 114, 1502-1512. [CrossRef]

14. McEniry, E.J.; Hickel, T.; Neugebauer, J.J. Hydrogen behaviour at twist $\{110\}$ grain boundaries in $\alpha$-Fe. Philos. Trans. A Math. Phys. Eng. Sci. 2017, 375, 20160402. [CrossRef] [PubMed]

15. McEniry, E.J.; Dey, P.; Hickel, T.; Neugebauer, J. Atomistic Modelling of Cosegregation at Structural Defects in Steels. SteelyHydrogen. Available online: http://steelyhydrogen2018proc.be/articles/atomistic-modellingof-cosegregation-at-structural-defects-in-steels/25 (accessed on 15 May 2020).

16. Zhao, Y.; Lu, G. QM/MM study of dislocation-Hydrogen/helium interactions in $\alpha$-Fe. Model. Simul. Mater. Sci. Eng. 2011, 19, 065004. [CrossRef]

17. Itakura, M.; Kaburaki, H.; Yamaguchi, M.; Okita, T. The effect of hydrogen atoms on the screw dislocation mobility in bcc iron: A first-principles study. Acta Mater. 2013, 61, 6857-6867. [CrossRef]

18. Tateyama, Y.; Ohno, T. Stability and clusterization of hydrogen-vacancy complexes in $\alpha$-Fe: An ab initio study. Phys. Rev. B 2003, 67, 1-2. [CrossRef]

19. Wang, F.; Shang, J.; Li, J.; Wang, C. The effects of boron and hydrogen on the embrittlement of polycrystalline Ni3Al. Intermetallics 2000, 8, 589-593. [CrossRef]

20. Qi, Y.; Hector, L.G. Hydrogen effect on adhesion and adhesive transfer at aluminum/diamond interfaces. Phys. Rev. B 2003, 1-4. [CrossRef]

21. Siegl, W.; Ecker, J.; Klarner, G.; Kloesch, G.; Mori, A.; Drexler, G.; Winter, H. Hydrogen Trapping in Heat Treated and Deformed Armco Iron; NACE International: Houston, TX, USA, 2019.

22. Mceniry, E.J.; Hickel, T.; Neugebauer, J. Atomistic modelling of light-element co-segregation at structural defects in iron. Procedia Struct. Integr. 2018, 13, 1099-1104. [CrossRef]

23. Lu, T.; Xu, Y.P.; Pan, X.D.; Zhou, H.S.; Ding, F.; Yang, Z.; Niu, G.J.; Luo, G.N.; Li, X.C.; Gao, F. Atomistic study of hydrogen behavior around dislocations in $\alpha$ iron. J. Nucl. Mater. 2018, 510, 219-228. [CrossRef]

24. Tateyama, Y.; Ohno, T. Atomic-scale effects of hydrogen in iron toward hydrogen embrittlement: Ab-initio study. ISIJ Int. 2003, 43, 573-578. [CrossRef]

25. Razumovskiy, V.I.; Divinski, S.V.; Romaner, L. Acta Materialia Solute segregation in Cu: DFT vs. Experiment. Acta Mater. 2018, 147, 122-132. [CrossRef]

26. Scheiber, D.; Razumovskiy, V.I.; Puschnig, P.; Pippan, R.; Romaner, L. Ab initio description of segregation and cohesion of grain boundaries in W-25 at.\% Re alloys. Acta Mater. 2015, 88, 180-189. [CrossRef] 
27. He, B.; Xiao, W.; Hao, W.; Tian, Z. First-principles investigation into the effect of Cr on the segregation of multi-H at the Fe $\Sigma 3$ (1 11 1) grain boundary. J. Nucl. Mater. 2013, 441, 301-305. [CrossRef]

28. Lu, T.; Niu, G.; Xu, Y.; Wang, J.; An, Z.; Liu, H.; Zhou, H.; Ding, F.; Luo, G.; Li, X. Molecular dynamics study of the diffusion properties of $\mathrm{H}$ in Fe with point defects. Fusion Eng. Des. 2016, 113, 340-345. [CrossRef]

29. Lv, G.; Zhang, M.; Zhang, H.; Su, Y. Hydrogen diffusion and vacancy clusterization in iron. Int. J. Hydrogen Energy 2018, 43, 15378-15385. [CrossRef]

30. Kimizuka, H.; Ogata, S. Slow diffusion of hydrogen at a screw dislocation core in $\alpha$-iron. Phys. Rev. B Condens. Matter Mater. Phys. 2011, 84, 1-6. [CrossRef]

31. Teus, S.M.; Mazanko, V.F.; Olive, J.M.; Gavriljuk, V.G. Grain boundary migration of substitutional and interstitial atoms in $\alpha$-iron. Acta Mater. 2014, 69, 105-113. [CrossRef]

32. Jiang, D.E.; Carter, E.A. Diffusion of interstitial hydrogen into and through bcc Fe from first principles. Phys. Rev. B Condens. Matter Mater. Phys. 2004, 70, 1-9. [CrossRef]

33. Sanchez, J.; Fullea, J.; Andrade, C.; De Andres, P.L. Hydrogen in $\alpha$-iron: Stress and diffusion. Phys. Rev. $B$ Condens. Matter Mater. Phys. 2008, 78, 1-7. [CrossRef]

34. Svoboda, J.; Fischer, F.D. Modelling for hydrogen diffusion in metals with traps revisited. Acta Mater. 2012, 60, 1211-1220. [CrossRef]

35. Fischer, F.D.; Mori, G.; Svoboda, J. Modelling the influence of trapping on hydrogen permeation in metals. Corros. Sci. 2013, 76, 382-389. [CrossRef]

36. Drexler, A.; Depover, T.; Verbeken, K.; Ecker, W. Model-based interpretation of thermal desorption spectra of Fe-C-Ti alloys. J. Alloys Compd. 2019, 789, 647-657. [CrossRef]

37. Drexler, A.; Depover, T.; Leitner, S.; Verbeken, K.; Ecker, W. Microstructural based hydrogen diffusion and trapping models applied to Fe-C-X alloys. J. Alloys Compd. 2020, 154057. [CrossRef]

38. Blöchl, P.E. Projector augmented-wave method. Phys. Rev. B 1994, 50, 17953-17979. [CrossRef] [PubMed]

39. Kresse, G.; Joubert, D. From ultrasoft pseudopotentials to the projector augmented-wave method. Phys. Rev. B 1999, 59, 1758-1775. [CrossRef]

40. Kresse, G.; Furthmüller, J. Efficiency of ab-initio total energy calculations for metals and semiconductors using a plane-wave basis set. Comput. Mater. Sci. 1996, 6, 15-50.

41. Kresse, G.; Hafner, J. Ab. initio molecular dynamics for liquid metals. Phys. Rev. B 1993, 47, 558-561. [CrossRef]

42. Kresse, G.; Hafner, J. Ab initio molecular-dynamics simulation of the liquid-metal-Amorphoussemiconductor transition in germanium. Phys. Rev. B 1994, 49, 14251-14269. [CrossRef]

43. Perdew, J.P.; Burke, K.; Ernzerhof, M. Generalized Gradient Approximation Made Simple. Phys. Rev. Lett. 1996, 77, 3865-3868. [CrossRef]

44. Monkhorst, H.J.; Pack, J.D. Special points for Brillonin-zone integrations. Phys. Rev. B 1976, 13, 5188-5192. [CrossRef]

45. Momma, K.; Izumi, F. VESTA: A three-dimensional visualization system for electronic and structural analysis. J. Appl. Crystallograph. 2008, 41, 653-658. [CrossRef]

46. Birch, F. Finite elastic strain of cubic crystals. Phys. Rev. B 1947, 71, 809-824. [CrossRef]

47. Murnaghan, F.D. The compressibility of media under extreme pressures. Proc. Natl. Acad. Sci. USA 1944, 30, 244-247. [CrossRef] [PubMed]

48. Razumovskiy, V.I.; Scheiber, D.; Razumovskii, I.M.; Butrim, V.N.; Trushnikova, A.S.; Varlamova, S.B.; Beresnev, A.G. New Cr-Ni-base alloy for high-temperature applications designed on the basis of first principles calculations. Adv. Condens. Matter Phys. 2018, 9383981. [CrossRef]

49. Ventelon, L.; Willaime, F. Core structure and Peierls potential of screw dislocations in $\alpha$-Fe from first principles: Cluster versus dipole approaches. J. Comput. Mater. Des. 2007, 14, 85. [CrossRef]

50. Segall, E.; Strachan, A.; Goddard, W.; Ismail-Beigi, S.; Arias, A. Ab initio and finite-temperature molecular dynamics studies of lattice resistance in tantalum. Phys. Rev. B Condens. Matter Mater. Phys. 2003, 68, 1-11. [CrossRef]

51. Cai, W.; Bulatov, V.V.; Chang, J.; Li, J.; Yip, S. Anisotropic elastic interactions of a periodic dislocation array. Phys. Rev. Lett. 2001, 86, 5727-5730. [CrossRef]

52. Li, J.; Wang, C.Z.; Chang, J.P.; Cai, W.; Bulatov, V.V.; Ho, K.M.; Yip, S. Core energy and Peierls stress of a screw dislocation in bcc molybdenum: A periodic-cell tight-binding study. Phys. Rev. B Condens. Matter Mater. Phys. 2004, 70, 1-8. [CrossRef] 
53. Li, H.; Wurster, S.; Motz, C.; Romaner, L.; Ambrosch-Draxl, C.; Pippan, R. Dislocation-core symmetry and slip planes in tungsten alloys: Ab initio calculations and microcantilever bending experiments. Acta Mater. 2012, 60, 748-758. [CrossRef]

54. Subramaniam, D.; Libisch, F.; Li, Y.; Pauly, C.; Geringer, V.; Reiter, R.; Mashoff, T.; Liebmann, M.; Burgdörfer, J.; Busse, C.; et al. Wave-function mapping of graphene quantum dots with soft confinement. Phys. Rev. Lett. 2012, 108, 46801. [CrossRef] [PubMed]

55. Romaner, L.; Razumovskiy, V.I.; Pippan, R. Core polarity of screw dislocations in Fe-Co alloys. Philos. Mag. Lett. 2014, 94, 334-341. [CrossRef]

56. Razumovskii, I.M.; Ruban, A.V.; Razumovskiy, V.I.; Logunov, A.V.; Larionov, V.N.; Ospennikova, O.G.; Poklad, V.A.; Johansson, B. New generation of Ni-based superalloys designed on the basis of first-principles calculations. Mater. Sci. Eng. A 2008, 497, 18-24. [CrossRef]

57. Finnis, M.W. The theory of metal-ceramic interfaces. J. Phys. Condens. Matter 1996, 8, 5811. [CrossRef]

58. Razumovskiy, V.I.; Lozovoi, A.Y.; Razumovskii, I.M. First-principles-aided design of a new Ni-base superalloy: Influence of transition metal alloying elements on grain boundary and bulk cohesion. Acta Mater. 2015, 82, 369-377. [CrossRef]

59. Rice, J.R.; Wang, J.S. Embrittlement of interfaces by solute segregation. Mater. Sci. Eng. A 1989, 107, $23-40$. [CrossRef]

60. Sutton, A.; Balluffi, R. Interfaces in Crystalline Materials; Oxford University Press: Oxford, UK, 1995.

61. Jain, A.; Ong, S.P.; Hautier, G.; Chen, W.; Richards, W.D.; Dacek, S.; Cholia, S.; Gunter, D.; Skinner, D.; Ceder, G.; et al. Commentary: The materials project: A materials genome approach to accelerating materials innovation. APL Mater. 2013, 1. [CrossRef]

62. Hayward, E.; Fu, C.C. Interplay between hydrogen and vacancies in $\alpha$-Fe. Phys. Rev. B Condens. Matter Mater. Phys. 2013, 87, 1-14. [CrossRef]

63. Haas, P.; Tran, F.; Blaha, P. Calculation of the lattice constant of solids with semilocal functionals. Phys. Rev. B Condens. Matter Mater. Phys. 2009, 79, 1-10. [CrossRef]

64. Forderer, K.I.; Doring, K.; Gladisch, M.; Haas, N.; Herlach, D.; Major, J.; Mundinger, H.; Rosenkranz, J.; Schafer, W.; Schimmele, L.; et al. $\mu+$ sr study of vacancies in thermal equilibrium in ferromagnets. Hyperfine Interact. 1986, 31, 81-86. [CrossRef]

65. Razumovskiy, V.I.; Ruban, A.V.; Korzhavyi, P.A. Effect of Temperature on the Elastic Anisotropy of Pure Fe and Fe_\{0.9\}Cr_\{0.1\} Random Alloy. Phys. Rev. Lett. 2011, 107, 205504. [CrossRef]

66. Ruban, A.V.; Razumovskiy, V.I. Spin-wave method for the total energy of paramagnetic state. Phys. Rev. B Condens. Matter Mater. Phys. 2012, 85, 1-10. [CrossRef]

67. Razumovskiy, V.I.; Ruban, A.V.; Korzhavyi, P.A. First-principles study of elastic properties of Cr- and Fe-rich Fe-Cr alloys. Phys. Rev. B Condens. Matter Mater. Phys. 2011, 84, 1-8. [CrossRef]

68. Razumovskiy, V.I.; Reyes-Huamantinco, A.; Puschnig, P.; Ruban, A.V. Effect of thermal lattice expansion on the stacking fault energies of fcc Fe and $\mathrm{Fe}_{75} \mathrm{Mn}_{25}$ alloy. Phys. Rev. B 2016, 93, 1-8. [CrossRef]

69. Rayne, J.A.; Chandrasekhar, B.S. Elastic constants of iron from 4.2 to $300^{\circ}$ K. Phys. Rev. 1961, 122, $1714-1716$. [CrossRef]

70. Kittel, C. Introduction to Solid State Physics; Wiley: Hoboken, NJ, USA, 1996; ISBN 9780471490210.

71. Söderlind, P.; Yang, L.; Moriarty, J.; Wills, J. First-principles formation energies of monovacancies in bcc transition metals. Phys. Rev. B 2000, 61, 2579-2586. [CrossRef]

72. Domain, C.; Becquart, C. Ab initio calculations of defects in Fe and dilute Fe-Cu alloys. Phys. Rev. B 2001, 65, 1-14. [CrossRef]

73. Olsson, P.; Domain, C.; Wallenius, J. Ab initio study of Cr interactions with point defects in bcc Fe. Phys. Rev. B Condens. Matter Mater. Phys. 2007, 75, 1-12. [CrossRef]

74. Momida, H.; Asari, Y.; Nakamura, Y.; Tateyama, Y.; Ohno, T. Hydrogen-enhanced vacancy embrittlement of grain boundaries in iron. Phys. Rev. B Condens. Matter Mater. Phys. 2013, 88, 31-33. [CrossRef]

75. Matsumoto, R.; Sera, M.; Miyazaki, N. Hydrogen concentration estimation in metals at finite temperature using first-principles calculations and vibrational analysis. Comput. Mater. Sci. 2014, 91, 211-222. [CrossRef]

76. Zu, X.T.; Yang, L.; Gao, F.; Peng, S.M.; Heinisch, H.L.; Long, X.G.; Kurtz, R.J. Properties of helium defects in bcc and fcc metals investigated with density functional theory. Phys. Rev. B Condens. Matter Mater. Phys. 2009, 80, 1-6. [CrossRef] 
77. Ohnuma, T.; Soneda, N.; Iwasawa, M. First-principles calculations of vacancy-solute element interactions in body-centered cubic iron. Acta Mater. 2009, 57, 5947-5955. [CrossRef]

78. Counts, W.A.; Wolverton, C.; Gibala, R. First-principles energetics of hydrogen traps in $\alpha$-Fe: Point defects. Acta Mater. 2010, 58, 4730-4741. [CrossRef]

79. Paxton, A.T.; Elsässer, C. Electronic structure and total energy of interstitial hydrogen in iron: Tight-binding models. Phys. Rev. B Condens. Matter Mater. Phys. 2010, 82, 13-15. [CrossRef]

80. De Schepper, L.; Segers, D.; Dorikens-Vanpraet, L.; Dorikens, M.; Knuyt, G.; Stals, L.M.; Moser, P. Positron annihilation on pure and carbon-doped -iron in thermal equilibrium. Phys. Rev. B 1983, 27, 5257-5269. [CrossRef]

81. Robertson, I.M.; Lillig, D.; Ferreira, P.J. Revealing the Fundamental Processes Controlling Hydrogen Embrittlmente. In Effects of Hydrogen on Materials; ASM International: Cleveland, OH, USA, 2009; pp. 22-37.

82. Liang, Y.; Sofronis, P.; Aravas, N. On the effect of hydrogen on plastic instabilities in metals. Acta Mater. 2003, 51, 2717-2730. [CrossRef]

83. Leyson, G.P.M.; Grabowski, B.; Neugebauer, J. Multiscale description of dislocation induced nano-hydrides. Acta Mater. 2015, 89, 50-59. [CrossRef]

84. Lynch, S.P. A fractographic study of hydrogen-assisted cracking and liquid-metal embrittlement in nickel. J. Mater. Sci. 1986, 21, 692. [CrossRef]

85. Barrera, O.; Bombac, D.; Chen, Y.; Daff, T.D.; Galindo-Nava, E.; Gong, P.; Haley, D.; Horton, R.; Katzarov, I.; Kermode, J.R.; et al. Understanding and mitigating hydrogen embrittlement of steels: A review of experimental, modelling and design progress from atomistic to continuum. J. Mater. Sci. 2018, 53, 6251-6290. [CrossRef]

86. Woodward, C.; Rao, S.I. Flexible Ab Initio Boundary Conditions: Simulating Isolated Dislocations in bcc Mo and Ta. Phys. Rev. Lett. 2002, 88, 4. [CrossRef]

87. Romaner, L.; Ambrosch-Draxl, C.; Pippan, R. Effect of rhenium on the dislocation core structure in tungsten. Phys. Rev. Lett. 2010, 104, 1-4. [CrossRef] [PubMed]

88. Vitek, V. Theory of the core structures of dislocations in body-centred-cubic metals. Cryst. Latt. Defects 1974, 5,1 .

89. Ventelon, L.; Willaime, F.; Clouet, E.; Rodney, D. Ab initio investigation of the Peierls potential of screw dislocations in bcc Fe and W. Acta Mater. 2013, 61, 3973-3985. [CrossRef]

90. Frederiksen, S.L.; Jacobsen, K.W. Density functional theory studies of screw dislocation core structures in bcc metals. Phil. Mag. 2003, 83, 365. [CrossRef]

91. Wan, L.; Geng, W.T.; Ishii, A.; Du, J.P.; Mei, Q.; Ishikawa, N.; Kimizuka, H.; Ogata, S. Hydrogen embrittlement controlled by reaction of dislocation with grain boundary in alpha-iron. Int. J. Plast. 2019, 112, 206-219. [CrossRef]

92. Iannuzzi, M.; Barnoush, A.; Johnsen, R. Materials and corrosion trends in offshore and subsea oil and gas production. NPJ Mater. Degrad. 2017, 1. [CrossRef]

93. Wang, S.; Martin, M.L.; Sofronis, P.; Ohnuki, S.; Hashimoto, N.; Robertson, I.M. Hydrogen-induced intergranular failure of iron. Acta Mater. 2014, 69, 275-282. [CrossRef]

94. Kim, S.M.; Buyers, W.J.L. Vacancy formation energy in iron by positron annihilation. J. Phys. F Met. Phys. 1978, 8, L103-L108. [CrossRef]

95. Maier, K.; Metz, H.; Herlach, D.; Schaefer, H.E. High temperature positron annihilation experiments in BCC metals. J. Nucl. Mater. 1978, 69, 589-592. [CrossRef]

96. Schaefer, H.E.; Maier, K.; Weller, M.; Herlach, D.; Seeger, A.; Diehl, J. Vacancy formation in iron investigated by positron annihilation in thermal equilibrium. Scr. Metall. 1977, 11, 803-809. [CrossRef]

97. Seeger, A. Lattice vacancies in high-purity $\alpha$-iron. Phys. Status Solidi 1998, 167, 289-311. [CrossRef]

98. Shin, Y.K.; Kwak, H.; Zou, C.; Vasenkov, A.V.; Van Duin, A.C.T. Development and validation of a ReaxFF reactive force field for $\mathrm{Fe} / \mathrm{Al} / \mathrm{Ni}$ alloys: Molecular dynamics study of elastic constants, diffusion, and segregation. J. Phys. Chem. A 2012, 116, 12163-12174. [CrossRef] [PubMed]

99. Bhattacharya, S.K.; Tanaka, S.; Shiihara, Y.; Kohyama, M. Ab initio study of symmetrical tilt grain boundaries in bcc Fe: structural units, magnetic moments, interfacial bonding, local energy and local stress. J. Phys. Condens. Matter 2013, 25, 135004. [CrossRef] [PubMed]

100. Mirzoev, A.A.; Mirzaev, D.A.; Verkhovykh, A.V. Hydrogen-vacancy interactions in ferromagnetic and paramagnetic bcc iron: Ab initio calculations. Phys. Status Solidi Basic Res. 2015, 252, 1966-1970. [CrossRef] 
101. Wang, J.; Madsen, G.K.H.; Drautz, R. Grain boundaries in bcc-Fe: A density-functional theory and tight-binding study. Model. Simul. Mater. Sci. Eng. 2018, 26. [CrossRef]

102. Wachowicz, E.; Ossowski, T.; Kiejna, A. Cohesive and magnetic properties of grain boundaries in bcc Fe with Cr additions. Phys. Rev. B Condens. Matter Mater. Phys. 2010, 81,1-9. [CrossRef]

103. Scheiber, D.; Pippan, R.; Puschnig, P.; Romaner, L. Ab initio calculations of grain boundaries in bcc metals. Model. Simul. Mater. Sci. Eng. 2016, 24, 35013. [CrossRef]

104. Tyson, W.R.; Miller, W.A. Surface free energies of solid metals: Estimation from liquid surface tension measurements. Surf. Sci. 1977, 62, 267-276. [CrossRef]

105. Boer, F.R.; Boom, R.; Mattens, W.C.M.; Miedema, A.R.; Niessen, A.K. Cohesion in Metals; North Holland: Amsterdam, The Netherlands, 1988.

106. Spencer, M.J.S.; Hung, A.; Snook, I.K.; Yarovsky, I. Density functional theory study of the relaxation and energy of iron surfaces. Surf. Sci. 2002, 513, 389-398. [CrossRef]

107. Jiang, D.E.; Carter, E.A. First principles assessment of ideal fracture energies of materials with mobile impurities: Implications for hydrogen embrittlement of metals. Acta Mater. 2004, 52, 4801-4807. [CrossRef]

108. Kuopanportti, P.; Hayward, E.; Fu, C.C.; Kuronen, A.; Nordlund, K. Interatomic Fe-H potential for irradiation and embrittlement simulations. Comput. Mater. Sci. 2016, 111, 525-531. [CrossRef]

109. Mishin, Y.; Sorensen, M.R.; Voter, A.F. Calculation of point-defect entropy in metals. Philos. Mag. A 2001, 81, 2591-2612. [CrossRef]

110. Hirth, J.P. Effects of hydrogen on the properties of iron and steel. Metall. Trans. A 1980, 11, 861-890. [CrossRef]

111. Christmann, K. Interaction of hydrogen with solid surfaces. Surf. Sci. Rep. 1988, 9, 1-163. [CrossRef]

112. Wipf, H. Solubility and diffusion of hydrogen in pure metals and alloys. Phys. Scr. 2001, T94, 43-51. [CrossRef]

113. Du, Y.A.; Ismer, L.; Rogal, J.; Hickel, T.; Neugebauer, J.; Drautz, R. First-principles study on the interaction of $\mathrm{H}$ interstitials with grain boundaries in $\alpha$ - and $\gamma$-Fe. Phys. Rev. B Condens. Matter Mater. Phys. 2011, 84, 1-13. [CrossRef]

114. Ohsawa, K.; Eguchi, K.; Watanabe, H.; Yamaguchi, M.; Yagi, M. Configuration and binding energy of multiple hydrogen atoms trapped in monovacancy in bcc transition metals. Phys. Rev. B Condens. Matter Mater. Phys. 2012, 85, 1-8. [CrossRef]

115. Besenbacher, F.; Myers, S.M.; Nordlander, P.; Nørskov, J.K. Multiple hydrogen occupancy of vacancies in Fe. J. Appl. Phys. 1987, 61, 1788-1794. [CrossRef]

116. Myers, S.M.; Follstaedt, D.M.; Besenbacher, F.; Bøttiger, J. Trapping and surface permeation of deuterium in He-implanted Fe. J. Appl. Phys. 1982, 53, 8734-8744. [CrossRef]

117. Ramasubramaniam, A.; Itakura, M.; Carter, E.A. Interatomic potentials for hydrogen in $\alpha$-iron based on density functional theory. Phys. Rev. B 2009, 79, 174101. [CrossRef]

118. Choo, W.Y.; Lee, J.Y. Thermal analysis of trapped hydrogen in pure iron. Met. Trans. A. 1982, 13, $135-140$. [CrossRef]

119. Bernstein, I.M. The effect of hydrogen on the deformation of iron. Scr. Metall. 1974, 8, 343-349. [CrossRef]

120. Pressouyre, G.M. A classification of hydrogen traps in steel. Metall. Trans. A 1979, 10,1571-1573. [CrossRef]

121. Hagi, H.; Hayashi, Y. Diffusion coefficients of hydrogen in carbon steels between 278 and $318 \mathrm{~K}$ and hydrogen trapping effect of interface between cementite and ferrite. Jpn. Inst. Met. 1993, 57, 864-869. [CrossRef]

122. Miodownik, G.M.; Achar, B.S. Proceedings of International Conference on "I'Hydrogene dans les Metaux"; Sciences-Industries: Paris, France, 1972.

123. Gibala, R. Internal friction in hydrogen-charged iron. Trans. Metall. Soc. AIME 1967, 239, 1574-1585.

124. Gibala, R.; Counts, W.A.; Wolverton, C. The hydrogen cold work peak in BCC iron: Revisited, with first principles calculations and implications for hydrogen embrittlement. Mater. Res. 2018, 21. [CrossRef]

125. Voronoi, G. Nouvelles applications des paramètres continus à la théorie des formes quadratiques. J. Reine Angew. Math. 1908, 133, 97-178. [CrossRef] 
126. Ventelon, L.; Lüthi, B.; Clouet, E.; Proville, L.; Legrand, B.; Rodney, D.; Willaime, F. Dislocation core reconstruction induced by carbon segregation in bcc iron. Phys. Rev. B Condens. Matter Mater. Phys. 2015, 91, 1-5. [CrossRef]

127. McLean, D. Grain Boundaries in Metals; Clarendon Press: Oxford, UK, 1957.

() $(1)$ (C) 2020 by the authors. Licensee MDPI, Basel, Switzerland. This article is an open access article distributed under the terms and conditions of the Creative Commons Attribution (CC BY) license (http://creativecommons.org/licenses/by/4.0/). 